\title{
RETORNO DE AÇÕES, INFLAÇÃO E ATIVIDADE ECONÔMICA
}

\author{
Nelson da Silva * \\ Sidney Martins Caetano ${ }^{\dagger}$
}

\begin{abstract}
Resumo
O trabalho investiga empiricamente as relações entre retorno de ações, inflação e atividade econômica para dados mensais brasileiros (1996-2017). Analisamos a variância e correlação wavelet e estimamos regressões em níveis de escala. Os resultados não corroboram a hipótese principal de que a relação negativa entre retorno real de ações e inflação seria induzida por uma relação negativa entre a inflação e a atividade econômica. Além disso, a relação entre retorno real de ações e a atividade econômica não é independente da inflação. Em termos de escala, na inflação e hiato do produto predominam ciclos de médio e longo prazos, enquanto na composição da taxa de crescimento da produção industrial e do retorno real do índice acionário, o componente de curto prazo é o determinante.
\end{abstract}

Palavras-chave: Retorno de Ativos-Inflação; Hipótese Proxy; Ondaletas.

\begin{abstract}
The paper empirically investigates the relations between stock return, inflation and economic activity for Brazilian monthly data (1996-2017). We analyzed the wavelet variance and correlation and estimated regres-sions at levels of scale. The results do not corroborate the main hypothe-sis that a negative relation between inflation and economic activity would induce the negative relation between real stock return and inflation. Furthermore, the relation between real stock return and economic activity is not independent of inflation. In terms of scale, cycles of medium and long terms predominate on the inflation and output gap, while in the composition of the industrial production growth rate and the real return of the stock index, the short-term component is the determinant.
\end{abstract}

Keywords: Stock Return-Inflation; Proxy Hypothesis; Wavelets.

JEL classification: C10, E31, E44.

DOI: http://dx.doi.org/10.11606/1980-5330/ea137954

\footnotetext{
* Departamento de Estudos e Pesquisas, Banco Central do Brasil. E-mail: nelson.silva@bcb.gov.br

${ }^{\dagger}$ Departamento de Economia, Universidade Federal de Juiz de Fora - UFJF. Bolsista de Produtividade em Pesquisa do CNPq. E-mail: sidney.caetano@ufjf.edu.br
} 


\section{Introdução}

A hipótese de Fisher afirma que retornos esperados de ativos nominais devem mover-se um para um com a inflação esperada, o que implicaria que retornos reais das ações seriam determinados por fatores reais e independentes da taxa de inflação. Ao contrário da teoria econômica e do senso comum, os retornos das ações estão negativamente relacionados à inflação esperada e inesperada, pois diversas são as evidências que corroboram essa intrigante relação negativa entre as duas variáveis, especialmente durante o período pós-guerra para os EUA e outras economias (ver Bodie (1976), Jaffe \& Mandelker (1976), Nelson (1976), Fama \& Schwert (1977), Lee (2010), entre outros). Esses resultados são intrigantes, dada a sabedoria previamente aceita de que as ações ordinárias, que representam a propriedade dos rendimentos gerados por ativos reais, devem ser uma proteção contra a inflação. No entanto, Geske \& Roll (1983) argumentam que esse enigmático fenômeno empírico não indica causalidade, apenas sinaliza uma cadeia de eventos que resulta de choques no produto. Ainda, outras explicações para essa relação negativa podem ser encontradas na literatura, por exemplo, por meio da Hipótese Proxy (Fama 1981), Hipótese de Efeitos Fiscais (Feldstein 1980), Hipótese de Ilusão Inflacionária (Modigliani \& Cohn 1979), Hipótese de Dois Regimes (Lee 2010), entre outras. Todavia, a falta de consenso faz da relação retorno de ações-inflação ainda um tópico importante na economia, gerando fatos empíricos bem estabelecidos para diferentes países.

A hipótese de Fama (1981) é a de que as relações negativas entre os retornos reais das ações e a inflação observadas durante o período pós-1953 são a consequência dos efeitos proxy. Os retornos das ações são determinados pelas previsões de variáveis reais mais relevantes, e as relações negativas de inflação e retorno das ações são induzidas por relações negativas entre inflação e atividade econômica real interpretadas no contexto da teoria da demanda por moeda e da teoria quantitativa da moeda. Ainda, os retornos das ações e as taxas de inflação estão mais fortemente relacionados (embora com sinais opostos) às medidas da atividade real futura. Nesse caso, a hipótese proxy implica que medidas de atividade real devem dominar medidas de inflação quando ambas são usadas como variáveis explicativas em regressões de retorno real de ativos. ${ }^{1}$

Conforme destaca Canova \& Nicoló (2000), a relação entre retorno de ações, inflação e atividade real está no centro da agenda de pesquisa dos economistas financeiros e da macroeconomia que tenta conciliar a moderna teoria do ciclo de negócios com as regularidades empíricas do mercado financeiro. É dentro dessa literatura, da enigmática relação retorno-inflação e da hipótese proxy dela derivada, que o presente trabalho se motiva a buscar evidências empíricas para a economia brasileira.

Dado que um resultado comum nas análises empíricas sobre a temática supracitada é que o grau de associação entre as variáveis depende da escala de tempo, a contribuição principal deste trabalho é explorar as seguintes relações em uma diversidade grande de frequências: i) a relação entre retorno de ações e inflação; ii) a relação entre retorno de ações e atividade econômica;

\footnotetext{
${ }^{1}$ Em dados mensais, trimestrais e anuais, as taxas de crescimento da moeda e da atividade real eliminam as relações negativas entre os retornos reais das ações e as taxas de inflação esperadas. Nas regressões de retornos anuais de ações, a surpresa inflacionária também perde seu poder explicativo quando colocada em competição com a atividade real futura (Fama 1981).
} 
e iii) a relação entre inflação e atividade econômica. Para isso, utiliza-se a abordagem wavelet. A vantagem dessa técnica em relação aos métodos usualmente empregados nessa literatura (muitas vezes análise de cointegração) é que ela permite tanto estimar o grau de correlação entre as variáveis em uma quantidade maior de frequências como verificar o desenrolar dessas relações ao longo do tempo. Outro ponto favorável ao método wavelet é que não há necessidade de se impor sobre os dados qualquer hipótese de estacionariedade.

A transformada wavelet representa um refinamento da análise de Fourier. Em particular, sua utilização permite ter em consideração quer o domínio do tempo quer o domínio da frequência de forma unificada, ou seja, é possível avaliar simultaneamente a relação entre variáveis em diferentes frequências e se essa relação tem evoluído ao longo do tempo. Então, a escolha metodológica permite a passagem para o domínio da frequência retendo informações do domínio do tempo, ainda que não completamente devido ao princípio da incerteza de Heizenberg.

Sobre o item (iii) acima, é importante ressaltar que análises do relacionamento do hiato com a inflação têm sido constantes na literatura macroeconômica, muito das vezes apoiada em alguma versão da Curva de Phillips, seja microfundamentada ou não. Isso se deve, principalmente, ao papel central que essa conexão assume na formulação e implementação da política monetária e ao frequente emprego em modelos de previsão da inflação. Muitas vezes, o hiato do produto decorre da aplicação do tradicional filtro HP e comparado a algum outro método. De forma a ser consistente com a metodologia, neste trabalho o hiato do produto também é derivado por meio da metodologia wavelet. Essa estimativa auxiliar representa uma contribuição adicional do artigo, juntamente com a investigação do papel do hiato sobre a dinâmica inflacionária brasileira combinando o domínio da frequência e do tempo.

Os estudos da relação entre retorno de ações, inflação e atividade econômica realizados com o método wavelet, que serão apresentados na Seção 2, são propensos a analisar pares de variáveis. De acordo com os trabalhos no domínio do tempo citados, essas relações também podem ser estudadas conjuntamente. Além de avaliar as variáveis por pares, outra contribuição deste trabalho é empregar a análise conjunta dessas relações por meio das técnicas de correlação wavelet parcial e múltipla desenvolvidas por Aguiar \& Soares (2011) e Fernández-Macho (2012), respectivamente.

Como destacado anteriormente, este trabalho utiliza a metodologia wavelet na análise integrada da relação entre retorno de ações, inflação e atividade econômica e a aplicação dessa metodologia faz sentido na medida em que essas relações podem variar de acordo com o horizonte de tempo ao qual essas variáveis são medidas. Assim, tanto a hipótese de Fisher na relação entre o retorno de ativos nominais e inflação, como o link entre retornos reais de ações e atividade econômica, que pode ser baseado no modelo fluxo de caixa descontado ou na hipótese de Fama (1981), e mesmo a relação entre inflação e atividade econômica, prescrita na curva de Phillips, podem depender da escala de medida dessas variáveis, com resultados distintos no curto, médio e longo prazos. A abordagem wavelet permite exatamente a decomposição das séries escala por escala.

A dependência do conceito de escala de tempo na relação entre a atividade econômica e retorno de ações é consequência dos horizontes temporais diferentes a que estão submetidas decisões motivadas por fins especulativos, equilíbrio da carteira, consumo não planejado ou investimentos financeiros 
de longo prazo. No caso da relação entre inflação e atividade econômica, o horizonte envolvido nas decisões das empresas e trabalhadores também é variado. No curto prazo, as empresas precisam decidir sobre o número de horas de trabalho, no médio, o redimensionamento da planta e, no longo prazo, a construção de novas unidades ou a produção em um local diferente, por exemplo. Aos trabalhadores, por outro lado, a negociação salarial abrange o nível atual de desemprego, a inflação passada, corrente e futura e ainda o eventual crescimento da produtividade (Gallegati 2008, Gallegati et al. 2011).

Assim, neste trabalho, o método wavelet é empregado nas suas versões discreta e contínua de forma a investigar as relações e hipóteses supracitadas nas diferentes escalas associadas com os diferentes horizontes temporais. Por meio dessas duas transformadas wavelet, utiliza-se a decomposição da variância relativa a cada escala permitindo derivar as covariâncias e correlações (simples, cruzadas, parciais e múltiplas) entre as séries em horizontes de tempo predefinidos. De forma complementar, faz-se uso de regressão no domínio do tempo usando as séries decompostas da análise de multirresolução da transformada discreta, o que significa a possibilidade de estimar regressões com séries das quais se tem informação exata do período de tempo a que pertecem, ou seja, curto, médio e longo prazo. Outro procedimento é a estimativa do hiato do produto por meio da metodologia wavelet, que no presente caso consiste da técnica de suavização bayesiana. Essa série permite um rápido exercício de robustez dos resultados previamentes obtidos com a série do hiato do produto derivada do filtro HP.

No que tange às hipóteses assumidas, apesar de que em algumas escalas a intrigante relação negativa entre retorno de ações e inflação se fazer presente, os resultados não corroboram a hipótese proxy de Fama (1981) no sentido de que a mesma seria induzida pela relação negativa entre a inflação e atividade econômica. Ainda, a relação entre retorno real de ações e atividade econômica não é independente da inflação, como implica a hipótese de Fisher.

De forma geral, os resultados mostram evidências de que a estrutura das séries não é a mesma em termos de escala. Em particular, na inflação e hiato do produto predominam as escalas de médio e longo prazos, enquanto na composição da taxa de crescimento da produção industrial e retorno real do índice acionário o componente de curto prazo é o determinante. A análise wavelet também revela que a relação entre as variáveis é bastante moderada ao longo do tempo e, quando existente, tende a se pronunciar nos momentos em que eventos anormais afetam significativamente a economia, como a última crise financeira internacional e a crise de confiança na economia brasileira no início dos anos 2000. Baseado na transformada wavelet contínua, o link entre o hiato do produto e a inflação parece ter se enfraquecido após meados de 2005 e a correlação do retorno real do Ibovespa com a atividade econômica mostrou-se concentrada no quadriênio 2008-2012, aproximadamente.

Além desta introdução, o presente trabalho está estruturado da seguinte forma: a seção 2 apresenta uma breve revisão empírica e teórica sobre as relações exploradas; a seção 3 tenta contribuir com maiores detalhes sobre wavelets, que se trata de uma técnica ainda pouco empregada no Brasil; a seção 4 mostra os resultados empíricos e suas discussões; e, por fim, a seção 5 destaca as principais considerações finais. 


\section{Referencial Empírico e Teórico}

Diversas são as evidências que corroboram a intrigante relação negativa entre inflação e retorno de ações, especialmente durante o período pós-guerra para os EUA e outras economias (Bodie (1976), Nelson (1976), Fama \& Schwert (1977), etc.). Especificamente, ao buscar explicações para tal relação negativa, Fama (1981) encontrou consistência dos dados com a hipótese de que as relações negativas entre as variáveis são proxies para relações positivas entre retorno de ações e variáveis reais que são determinantes fundamentais de valores patrimoniais.

As relações retorno de ações-inflação negativas são, portanto, induzidas por relações negativas entre inflação e atividade real que, por sua vez, são explicadas por uma combinação de teoria de demanda por moeda e teoria quantitativa de moeda. Aqui, a relação negativa supracitada refere-se ao fenômeno da estagflação, situação na qual ocorre simultaneamente uma queda no nível de produção e um aumento nos preços, ou seja, a combinação entre estagnação econômica e inflação. Essa relação contraria a existência de uma Curva de Phillips Novo Keynesiana, em que esta afirma que a taxa de inflação corrente é função do hiato do produto corrente e da expectativa corrente para a inflação do próximo período, tal que a inflação, em $t$, relaciona-se positivamente com as expectativas de inflação e a atividade econômica representada pelo hiato do produto. Em seu Prêmio Nobel, Akerlof (2002) disse que "Probably the single most important macroeconomic relationship is the Phillips curve" (Mankiw \& Reis 2010). Ele certamente tem razão em dizer que esse relacionamento tem desempenhado um importante papel em muitas teorias do ciclo de negócios ao longo do último meio século. Não menos importante, entretanto, a curva também tem sido controversa e enigmática.

No que diz respeito à aplicação da metodologia wavelet nessas questões, do lado da relação entre o retorno de ações com a inflação ou a atividade econômica encontram-se os trabalhos de Gallegati (2008) e Kim \& In (2005). Do lado do estudo da inflação e sua relação com o hiato do produto ou desemprego, pode-se citar Tiwari et al. (2014), Pimentel (2013) - usando dados brasileiros (desemprego) -, e Gallegati et al. (2011).

Gallegati (2008) analisou a relação entre o retorno do mercado acionário e a atividade econômica americana, com dados mensais entre 1961 e 2006 . O retorno do índice de ações tende a antecipar movimentos da atividade econômica, medida pelo índice de produção industrial. Contudo, essa conclusão é válida somente no caso de ciclos superiores a 16 meses. Essa evidência estatística corrobora a visão teórica de que os investidores com objetivos de longo prazo levam em conta os fundamentos macroeconômicos nas suas decisões. Kim \& In (2005) testam a hipótese de Fisher que estabelece uma relação positiva entre retornos de ações nominais e inflação. Para tanto, utilizam regressão no domínio wavelet e a análise de correlação wavelet em dados americanos. Segundo os autores, a decomposição em escala de tempo fornece uma visão considerável para se testar a hipótese de Fisher. Seus resultados mostram relação positiva no curto prazo e negativa nas demais escalas. Da análise de correlação ainda é encontrado uma relação positiva no longo prazo. A hipótese de Fisher é verificada em ativos de risco no curto e longo prazo. Os retornos das ações não desempenham um papel de hedge com inflação durante o período amostral, exceto para escalas de curtíssimo e longo prazos na análise wavelet.

Tiwari et al. (2014) aplicam a análise wavelets discreta e contínua de forma 
a estudar a relação entre o hiato do produto e a inflação francesa. Os autores observam poder preditivo do hiato do produto em relação à dinâmica inflacionária de curto e médio prazos, tendo importantes implicações para a teoria da curva de Phillips. Ainda, a análise wavelets discreta mostra que as flutuações de curto e médio prazos de ambas as variáveis são estreitamente correlacionadas, enquanto que a análise contínua indica movimentos do hiato do produto à frente da inflação em horizontes de curto e médio prazos. De forma geral, concluem que o hiato do produto deve ser considerado um elemento importante na análise da curva de Phillips Novo Keynesiana, em que o hiato tem importantes implicações para a política monetária do BCE.

Gallegati et al. (2011) estão interessados em rever a relação entre inflação salarial e desemprego, cuja base tem a curva de Phillips original (Phillips 1958). A motivação é olhar os dados da economia americana pós-guerra por meio da análise wavelet que permite decompor as variáveis em suas componentes escala-tempo para então estimar a curva de Phillips original escala por escala. Isso os levam à questão da estabilidade da relação entre as frequências e ao longo do tempo. As regressões estimadas mostraram heterogeneidade nas escalas temporais, o que seria uma indicação de não linearidade na relação salário-desemprego. Ainda, em escalas de tempo mais longas encontram fortes significâncias estatísticas e relevantes proporções que explicam a variação total das mudanças nos salários nominais. Portanto, resultados indicando relação presente na curva de Phillips restrita aos componentes de menor frequência dos dados. Além da instabilidade presente nas frequências, mostra-se uma estabilidade relevante da relação durante o período 1948-93, levando-os a concluir que os resultados wavelet são consistentes com os insights originais de Phillips.

Pimentel (2013), por sua vez, emprega a metodologia wavelet na investigação da dinâmica inflacionária brasileira considerando como guia a curva de Phillips na sua versão Friedman-Phelps. Especificamente, verifica a hipótese de Friedman-Phelps, segundo a qual se deve esperar uma correlação negativa entre os preços e o desemprego no curto prazo. Os dados desse estudo corresponderam ao índice de preços ao consumidor, a taxa de desemprego e a variação do salário mínimo, abrangendo o período de janeiro de 1980 a fevereiro de 2011. Os resultados, derivados da transformada wavelets discreta, revelam que a hipótese da curva de Phillips para a economia brasileira não se verifica no curto prazo, mas sugerem a sua validade no longo prazo. Embora os resultados apresentem novos insights sobre a curva de Phillips no Brasil em termos de uma representação tempo-escala, torna-se importante explorar a robustez das propriedades da relação entre inflação e hiato do produto na medida em que seus resultados violam a hipótese da curva de Phillips Novo Keynesiana que implicaria verticalidade no longo prazo.

Para fins de abrangência, ainda que não estejam diretamente relacionados com a técnica empregada neste artigo, destaca-se a seguir alguns trabalhos sobre a temática proposta cuja abordagem consiste de métodos no domínio do tempo.

Gultekin (1983) investiga a relação entre retornos de ações e inflação em vinte e seis países para o período pós-guerra, com o objetivo de testar a hipótese generalizada de Fisher. Seus resultados, baseados em regressões de séries temporais, não corroboram a Hipótese de Fisher de que as taxas reais de retorno de ações e as taxas de inflação esperadas são independentes e que os retornos nominais das ações variam em correspondência de um para um 
com a inflação esperada. Ainda, os coeficientes de regressão são predominantemente negativos, a relação retorno-inflação é instável ao longo do tempo e existem diferenças entre os países. O autor destaca que países com taxas de inflação mais elevadas geralmente têm retornos de ações nominais mais altos, enquanto as taxas reais na maioria dos países têm estado em declínio desde meados da década de 1960. Sua conclusão é a de que a relação entre retornos de ações e inflação em outros países é tão enigmática quanto as observadas na economia americana.

Alagidede \& Panagiotidis (2012) examinam a relação contemporânea entre retorno de ativos e inflação para os países do G7 por meio de regressões quantílicas após mostrarem relação negativa e significativa para EUA e relações não significativas para as demais economias. Alguns coeficientes positivos na calda superior da distribuição são encontrados para a Itália e o Reino Unido. Ainda, usando um filtro GARCH, encontram evidências de que todos os coeficientes OLS (e GARCH) são significativos e próximos da unidade, com exceção do Canadá, onde este último ainda é positivo e significativo. Esses resultados são confirmados com a regressão quantílica da qual são obtidos coeficientes de unidade significativos em todos os países, exceto no Canadá.

Canova \& Nicoló (2000) analisam as interdependências empíricas entre retornos de ações, atividade real e inflação de vários países e buscam construir um conjunto de fatos estilizados diante de importantes assimetrias internacionais na dinâmica dos dados. Os autores constatam que as inovações nos retornos nominais das ações não estão significativamente relacionadas à inflação ou à atividade real em todos os países. Ainda, a estrutura de taxas de juros dos EUA prediz tanto as taxas de inflação doméstica e externa quanto a atividade real futura doméstica e que as inovações na inflação não afetam significativamente a atividade real.

Nunes et al. (2005) propõem analisar a relação entre variáveis macroeconômicas e retornos do Ibovespa no período pós-Plano Real. Seus resultados não corroboram a relação negativa entre inflação e atividade econômica. Ainda, variações do Ibovespa e PIB real não apresentaram relação significativa. Portanto, a hipótese proxy não se mantém diante de seus dados e procedimentos tradicionais empíricos. Entretanto, os resultados tendem a confirmar a suposição inerente à curva de Phillips (relação positiva entre inflação e a atividade econômica em termos reais).

Terra (2006) desenvolve uma análise de autorregressão vetorial (VAR) de forma a investigar as relações entre retornos reais das ações, taxas de juros reais, atividade real e inflação. Sua análise é aplicada aos dados da Alemanha, Canadá, França, Itália, Japão, Reino Unido e Estados Unidos. Os resultados principais não confirmam as ações como hedge para inflação e mostram que as diferenças entre países industrializados e países em desenvolvimento não são marcantes como presumido inicialmente. Ainda, os resultados, em geral, sugerem que a evidência norte-americana não pode ser generalizada mundialmente.

Segundo Lee (2010), dentre as diversas hipóteses que têm sido propostas para explicar a relação retorno de ações-inflação, a hipótese de ilusão inflacionária de Modigliani e Cohn é a que tem recebido atenção renovada. Outra hipótese que ele propõe é a hipótese de dois regimes. Ao analisar tais hipóteses usando dados dos EUA e de outras economias internacionais, o autor chega a resultados que mostram que a hipótese de ilusão inflacionária pode explicar a relação negativa retorno de ações-inflação pós-guerra, mas não é compatível 
com a relação positiva pré-guerra. Contudo, usando o método de identificação VAR estrutural, ele mostra a existência de dois regimes com relações positivas e negativas entre inflação e retorno de ações, não apenas em cada período dos EUA, mas também em todos os países desenvolvidos que considera. Isso parece inconsistente com a hipótese de ilusão inflacionária que prevê apenas a relação negativa.

Diante dessa literatura e dado que um resultado comum nas análises empíricas sobre a temática supracitada é que o grau de associação entre as variáveis depende da escala de tempo, o presente trabalho contribui explorando as relações levantadas em uma diversidade de frequências. A vantagem da técnica aqui proposta em relação aos métodos usualmente empregados é que ela permite tanto estimar o grau de correlação entre as variáveis em uma quantidade maior de frequências como verificar o desenrolar dessas relações ao longo do tempo. Outro ponto favorável ao método wavelet é que não há problema em se trabalhar com dados não estacionários. Em particular, sua utilização permite ter em consideração quer o domínio do tempo quer o domínio da frequência de forma unificada, ou seja, é possível avaliar simultaneamente a relação entre variáveis em diferentes frequências e se essa relação tem evoluído ao longo do tempo. Então, a escolha metodológica permite a passagem para o domínio da frequência retendo informações do domínio do tempo, ainda que não completamente devido ao princípio da incerteza de Heizenberg. Portanto, a aplicação da metodologia faz sentido na medida em que as relações podem variar de acordo com o horizonte de tempo ao qual as variáveis são medidas. Assim, tanto a hipótese de Fisher na relação entre o retorno de ativos nominais e inflação, como o link entre retornos reais de ações e atividade econômica, que pode ser baseado no modelo fluxo de caixa descontado ou na hipótese de Fama (1981), e mesmo a relação entre inflação e atividade econômica, prescrita na curva de Phillips, podem depender da escala de medida dessas variáveis, com resultados distintos no curto, médio e longo prazos. A abordagem wavelet permite exatamente a decomposição das séries escala por escala.

\section{Metodologia e os Dados}

\subsection{Transformada Wavelet}

A análise wavelet é uma ferramenta estatística que, a um certo tradeoff, permite traduzir a informação contida em uma série simultaneamente para os domínios do tempo e da frequência. A aproximação de uma função pela combinação recursiva de duas funções base, denominadas wavelet e de escala, é o meio de representar a série no chamado domínio tempo-escala. Os componentes de baixa e alta frequência da série são identificados e localizados no tempo por meio de dilatações e compressões das funções base. Portanto, essa técnica favorece o estudo de fenômenos periódicos em que as frequências se alteram no decorrer do tempo. Um dos fatores que despertam o interesse da aplicação desse método em economia é a constatação de que diversas séries econômicas são caracterizadas por essa dinâmica. ${ }^{2}$

\footnotetext{
${ }^{2} \mathrm{~A}$ análise de séries temporais via o método wavelet, como observam Gallegati et al. (2011) em um estudo da curva de Phillips para os Estados Unidos, é relativamente recente e de aplicação usual em diferentes áreas do conhecimento científico, mas seu uso em economia ainda é um pouco restrito. Como destacam esses autores, porém, um método novo é uma oportunidade de observar fatos antigos sob uma nova ótica. Ainda segundo esses autores, dado que o procedimento de
} 
Há duas versões de transformada wavelet: contínua e discreta. As duas são utilizadas isoladamente ou de forma complementar nos trabalhos em economia. De certa forma, existe a predominância da versão discreta e a descrição a seguir começa por ela, embora historicamente a transformada contínua tenha surgido primeiro. O enfoque desta seção é mais descritivo, voltado a estabelecer um vocabulário básico do método. Os Apêndices A e B ao final do trabalho contêm um tratamento mais formal do assunto e referências, as quais serviram de base para esta seção.

A transformada wavelet discreta decompõe a série em grupos de coeficientes. Cada grupo é associado a uma escala e cada coeficiente dentro desse conjunto tem uma localização própria no tempo. A parte suave, associada à tendência (baixa frequência), é obtida por meio da projeção do sinal sobre formas modificadas de uma função de escalonamento (função escala). As modificações da função escala são decorrentes das operações de compressão e dilatação, bem como do deslocamento no tempo. Os detalhes (alta frequência), os coeficientes wavelet, são obtidos por projeção similar em uma função wavelet. Em cada escala, é possível identificar na coleção de coeficientes wavelet variações significativas nos dados e, em termos espectrais, associá-los a ciclos de duração específica.

Um aspecto interessante da transformada wavelet é a possibilidade de decompor a variância da série em partes designadas a cada escala. A interpretação pode se basear no mesmo que acontece na decomposição da densidade espectral na análise de Fourier clássica. Adicionalmente, intervalos de confiança também podem ser determinados. Uma vez que a variância tenha sido estabelecida, a covariância entre duas séries temporais pode ser derivada e decomposta por escala. Dadas a variância e a covariância wavelet, a combinação dessas levam ao cálculo da correlação para cada escala.

A transformada wavelet discreta pode ser calculada por diversos algoritmos. Um método que tem se tornado popular é denominado Maximal Overlap Discrete Wavelet Transform (MODWT), apresentado em Percival \& Walden (2000). Uma das vantagens desse algoritmo é a possibilidade de ser usado para qualquer tamanho de amostra, ao passo que o método tradicional se restringe às amostras divisíveis por $2^{J}$, onde $J$ é o nível máximo de decomposição. Outro ponto a favor da MODWT é que o procedimento não é variável aos deslocamentos cíclicos da série. Ainda, ele contempla as funções usuais de decomposição e análise de variância, sendo assimptoticamente mais eficiente nesse último caso.

Não é possível um único filtro wavelet cobrir todos os tipos de série. Há uma família de filtros disponíveis e a escolha do mais adequado é uma questão importante. Do ponto de vista prático, o filtro Daubechies least asymmetric (LA), com extensão igual a 8, denotado por LA(8), tem sido bastante aplicado nos trabalhos empíricos em economia. Interessante observar dois pontos: i) o comprimento do filtro implica um tradeoff entre aproximar o filtro a um passa baixa ideal e ter coeficientes não afetados pelas condições de borda e; ii) os filtros Daubechies são convenientes na análise de séries temporais porque produzem um alinhamento mais preciso entre os coeficientes wavelets, nas

Phillips nas estimações incorreu na substituição de dados brutos por médias, o que se assemelha a um filtro wavelet básico, incidentalmente (a teoria wavelet foi desenvolvida nos anos 1980) podese dizer que o próprio Phillips foi um dos primeiros a utilizar a técnica wavelet. Gençay \& Fan (2007) citam um trabalho de 1997 como um dos primeiros a reconhecer a importância dos filtros wavelets em econometria. 
variadas escalas, e a série temporal original, (Gallegati \& Gallegati 2007) e (Gallegati 2008).

Por sua vez, a transformada contínua detecta a correlação entre a série e uma função wavelet qualquer em uma determinada escala (frequência) e localização no tempo. A série é multiplicada por essa função que depende dos parâmetros de escalonamento $(s)$ e translação $(\tau)$, que controlam a extensão e a localização da função base e assumem valores contínuos. O processo ocorre da seguinte forma: primeiro, escolhe-se uma função base e uma escala, $s=1$, por exemplo. A função base, então, é posicionada no início do horizonte temporal $(\tau=0)$, multiplicada pela série e integrada em todos os períodos. O valor resultante é proporcional à transformada no ponto $(s, \tau)=(1,0)$. Na mesma escala, a função base é deslocada para a direita para a localização $\tau=t$, gerando o ponto da transformada em $(s, \tau)=(1, t)$. O processo é repetido até que se alcance o ponto final da série. Esse procedimento determina todos valores da transformada na escala $s=1$. Em seguida, os valores de $s$ são acrescidos de um pequeno montante até se mapear todas possibilidades de $s$, encerrando o cálculo da transformada wavelet contínua.

A primeira etapa do cômputo da transformada é a escolha da função $w a-$ velet analisadora (também chamada de função wavelet-mãe) que servirá de protótipo para as diversas versões comprimidas e dilatadas pelo parâmetro de escala. Existem variados tipos de funções wavelets e a escolha depende do propósito da análise. A função wavelet de Morlet é uma escolha tradicional quando o objetivo recai no estudo de mudanças de amplitude e fase, o que é essencial para analisar o sincronismo entre variáveis. Essa função tem valor complexo e a transformada pode ser dividida nas partes real e imaginária. Essa propriedade é desejável quando se busca calcular a fase da transformada de cada série, o que leva ao conhecimento dos avanços e atrasos das oscilações de uma em relação à outra nas diversas frequências e localização temporal.

Uma medida importante da transformada contínua é o espectro de potência. Ele pode ser interpretado como um indicador da distribuição da variância da série temporal no plano tempo-frequência. Outro conceito relevante é o espectro cruzado wavelet. Por meio dele, pode-se conhecer a covariância entre duas variáveis no espaço tempo-frequência. Um terceiro componente de interesse é a transformada coerência. Ela pode ser interpretada como um coeficiente de correlação local entre as séries, explicando quanto da variabilidade de uma pode ser explicada pela da outra em tempo-frequência.

\subsection{Os dados}

As séries usadas neste trabalho foram extraídas da base de dados do IPEADATA e do Banco Central do Brasil e compreendem a inflação (medida pela variação percentual do IPCA), o índice Bovespa e o índice de quantum da produção industrial da indústria geral. Os dados são mensais, cobrindo o período de jan./1996 a jan./2017. O retorno nominal do Ibovespa é obtido pela variação percentual mensal do índice, enquanto o retorno real é a série nominal deflacionada pelo IPCA. O hiato do produto foi calculado pela diferença entre a produção industrial e a tendência obtida pelo filtro $\mathrm{HP}^{3}{ }^{3}$

\footnotetext{
${ }^{3}$ De 1996 a 2001, os dados da produção industrial correspondem à série calculada pela metodologia antiga do IBGE, tendo a mesma sido descontinuada em fev./2014. A unificação das duas séries foi feita com base na variação mensal da antiga. A tendência da produção industrial foi obtida do filtro HP da série dessazonalizada pela metodologia TRAMO-SEATS. Para esse pro-
} 
Em razão da disponibilidade de dados mensais, o emprego da produção industrial como uma proxy para o PIB é uma alternativa encontrada em alguns estudos que demandam uma quantidade maior de observações e que utilizam a metodologia wavelets, ver Gallegati \& Gallegati (2007), Mitra et al. (2011) e Tiwari et al. (2014). Destaca-se a alegação empírica de Gallegati \& Gallegati (2007) para o uso da produção industrial. Segundo esses autores, embora o peso do setor de serviços nas economias industrializadas possa comprometer o papel da produção industrial como um bom indicador da atividade econômica, existem evidências de que os resultados obtidos com a produção industrial são qualitativamente similares aos obtidos usando o PIB. Além disso, como argumenta Mitra et al. (2011), a produção industrial reflete, de alguma forma, o nível de utilização efetiva dos recursos produtivos, como tecnologia, matéria-prima e trabalho e, em uma perspectiva global, ocorre a difusão do desempenho do setor industrial sobre a economia como um todo. Todavia, limitações sempre devem ser consideradas.

\section{Resultados Empíricos}

\subsection{Abordagem discreta: transformada MODWT e variância}

As séries da inflação, hiato do produto, taxa de crescimento da produção industrial e retorno real do Ibovespa foram decompostas com base na metodologia MODWT usando o filtro LA(8), que tem o potencial de tornar estacionária uma série integrada até a quarta ordem. ${ }^{4}$ Os resultados podem ser vistos nos gráficos da Figura 1, nos quais são apresentados os 7 conjuntos de coeficientes wavelets $\left(\mathrm{d}_{j}, j=1, \ldots, 7\right)$ e os coeficientes de escala (s7), calculados segundo as equações (5) e (6) exibidas no Apêndice.

Os coeficientes wavelets de um determinado nível $j$ podem ser vistos como diferenças entre duas médias (ponderadas) observadas na escala $\lambda_{j}=2^{j-1}$. Por exemplo, os coeficientes wavelets d1 da Figura 1 representam mudanças entre dois meses consecutivos, $\mathrm{d} 2$ variações entre médias bimestrais $\left(\lambda_{2}=2^{2-1}\right) \mathrm{e}$ assim sucessivamente. A banda de frequência do filtro MODWT, em ciclos por unidade de tempo, compreende os intervalos $\left[2^{-(j+1)}, 2^{-j}\right), j=1, \ldots, J$, em que $J$ é o nível máximo de decomposição, dado pelo maior número inteiro que não é maior ou igual a $\log _{2}(N)$, em que $N$ é o número de observações. No presente caso, $J=7$. A região correspondente em unidades de tempo (período) é dada pelo inverso da região de frequência, $\left(2^{j}, 2^{j+1}\right]$.Gallegati \& Gallegati (2007), Polanco-Martínez \& Abadie (2016)

Seguindo a definição usual de ciclos de negócios, no qual a flutuação cíclica se concentra no intervalo entre 1,5 a 8 anos, pode-se classificar os coeficientes da Figura 1 da seguinte forma. Os níveis 1 a 3 (d1 a d3), abrigando os componentes de frequência alta e muito elevada, representam a dinâmica de curto

cedimento, utilizou-se uma série maior iniciada em janeiro de 1975, sendo a variação mensal o procedimento para unificar os dados provenientes de diferentes metodologias do IBGE. O hiato corresponde à diferença logarítmica entre série dessazonalizada e a tendência. Os resultados descritos adiante são qualitativamente similares quando se aplica a dessazonalização e o filtro HP nos dados da produção industrial a partir de jan./1996.

${ }^{4}$ Como pode ser visto em Percival \& Walden (2000, p. 368-369), o filtro wavelet Daubechies de comprimento $L$ corresponde a uma operação implícita de diferenciação cuja ordem é $L / 2$, com a propriedade de reduzir a zero uma tendência polinomial de ordem $r$ se $\frac{L}{2} \geq r+1$. Os exercícios foram realizados com outros filtros, como o Haar e o filtro Daubechies de tamanho 4 (D4), sem alterações significativas dos resultados apresentados adiante. 
prazo. Os níveis 4 a 6 abrangem o período padrão dos ciclos de negócios. A tendência, componente de baixa frequência, é capturada pelos coeficientes do nível 7 (d7 e s7) Gallegati \& Gallegati (2007).

O que os gráficos da Figura 1 mostram é que até meados de 2003 havia maior volatilidade nos ciclos de curto prazo no caso da inflação, gráfico (a). Entre jan./2006 a jun./2008, a predominância dos movimentos da inflação concentrou-se na região dos ciclos de negócios, voltando a apresentar ciclos de curto prazo a partir de 2012, aproximadamente. Consistente com as propriedades do filtro HP, no hiato do produto há um formato cíclico bem evidente nos níveis $\mathrm{d} 3$ a d5, compreendendo períodos na região padrão do ciclo de negócios, (b). Entre ago./12 até meados de 2015, o hiato de produto apresentou um ciclo relevante no nível $\mathrm{d} 4$, ou seja, período entre 1 ano e 4 meses a 2 anos e 8 meses. Como se observa no item (c), a taxa de crescimento da produção industrial concentra as maiores variações nos coeficientes wavelets de alta frequência. A volatilidade do retorno real do Ibovespa recai predominantemente nos níveis de alta frequência; os ciclos de 2 a 4 meses (d1) foram de magnitude maior entre 1998 e 2003, painel (d).

Figura 1: Decomposição MODWT da inflação, hiato, produção industrial e retorno real do Ibovespa.

(a) Inflação (IPCA)

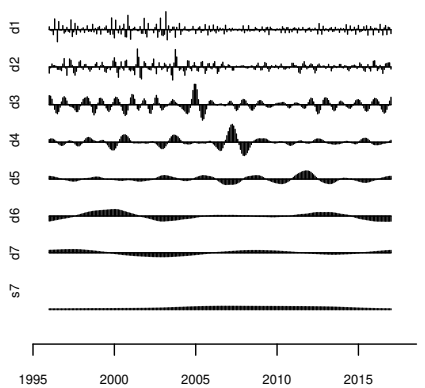

(c) Tx. de cres. da prod. industrial

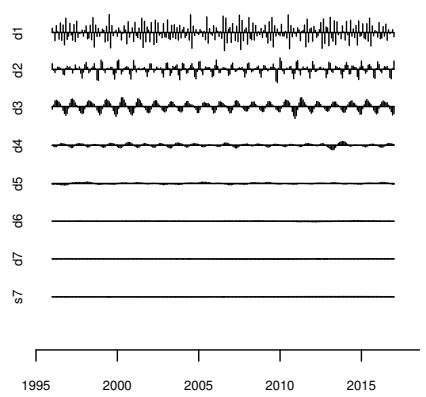

(b) Hiato do produto (produção industrial)

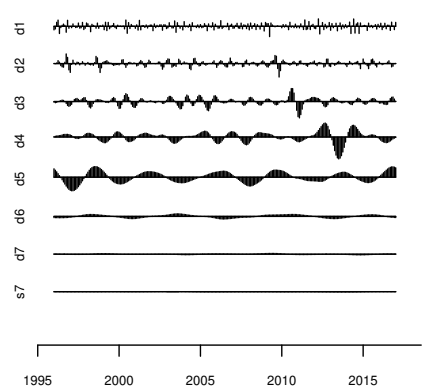

(d) Retorno real do ibovespa

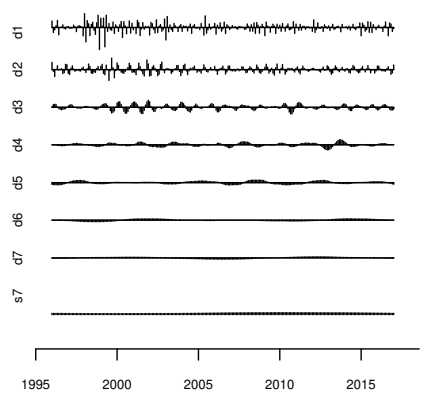

Avançando no estudo das propriedades de escala das variáveis e no intuito de estabelecer quanto cada escala contribuiu na formação da variância total 
das séries, apresenta-se a seguir a análise wavelet da variância, que indica a importância relativa dos ciclos de curto, médio e longos prazos. Dessa forma, a Tabela 1 mostra a proporção da variância de cada escala em relação ao total. Para obter um estimador sem viés, no cálculo da variância os coeficientes afetados pela condição de borda são excluídos, como pode ser notado na equação (7) do Apêndice.

Com base na Tabela 1, cerca de $60 \%$ da variância da inflação pode ser atribuída aos movimentos observados nas escalas 4 e 8 (níveis d3 e d4 na tabela), o que pode ser entendido como a variância dos ciclos de período entre 8 meses e 2 anos e 8 meses. Esse padrão sugere a influência maior de choques de oferta na dinâmica inflacionária. ${ }^{5}$

No caso do hiato do produto, o percentual maior da variância pode ser atribuído aos movimentos observados na escala 8. A flutuação nessa escala pode ser pensada como refletindo a diferença entre duas médias ponderadas de 8 meses ou, alternativamente, a variância dos ciclos de período entre 16 a 32 meses. Da mesma forma, quando se compara médias de 1 ano e 4 meses (escala 16, nível d5), a volatilidade do hiato do produto também é relevante. Em resumo, 70\% da flutuação da atividade econômica estaria sendo explicada pelos movimentos nas escalas 8 e 16 .

Já a variância da taxa de crescimento da produção industrial e do retorno real do Ibovespa apresenta, nos dois casos, relação inversa com o tamanho da escala wavelet, onde a variabilidade está associada a ciclos de curto prazo. Gallegati (2008) encontrou relação semelhante para o produto industrial americano. Esse resultado é esperado dado que no curto prazo o produto é afetado tanto por choques na demanda como na oferta.

No caso do Ibovespa, a frequência mais alta desse ciclo, nível d1, explica $50 \%$ da volatilidade. Outros $23 \%$ da variância são creditados aos movimentos na escala 2, ou seja, às diferenças entre as médias de 2 meses. Entretanto, os ciclos de médio e longo prazos são irrelevantes na explicação desses movimentos. Tal resultado é consistente com Pimentel \& Silva (2011), onde os autores mostraram que a volatilidade dos índices acionários decresce conforme a escala wavelet aumenta. Levando em conta as razões especulativas, ajuste de carteira, aumento inesperado no consumo e aplicações de longo prazo, esse padrão é desfavorável à eventual hipótese de o mercado ser expressivamente composto por agentes movidos por objetivos de longo prazo, guiados em suas decisões pelos fundamentos econômicos.

Em resumo, o estudo preliminar das propriedades de escala das séries mostra evidências de que na composição da inflação e do hiato do produto predominam as escalas de médio e longo prazos, ao passo que os termos de curto prazo são os mais relevantes para o retorno real de ações e o crescimento da produção industrial.

\subsection{Abordagem discreta: correlação wavelet - simples e múltipla, contemporânea e cruzada}

Uma possibilidade interessante da análise wavelet é avaliar o grau de associação entre duas séries por escalas de tempo e bandas de frequência. Os resultados estão plotados na Figura 2, ilustrando a correlação wavelet entre as

\footnotetext{
${ }^{5}$ Com base na inspeção visual dos coeficientes MODWT, resultado semelhante é encontrado em Pimentel (2013) para o período 1980-2011.
} 
Tabela 1: Decomposição da variância para a inflação, hiato do produto, retorno real do Ibovespa e crescimento da produção industrial.

\begin{tabular}{ccccccc}
\hline $\begin{array}{c}\text { Coeficientes } \\
\text { wavelets }\left(\mathbf{d}_{j}\right)\end{array}$ & $\begin{array}{c}\text { Escala } \\
\lambda_{j}=2^{j-1}\end{array}$ & $\begin{array}{c}\text { Ciclos } \\
\text { (meses) }\end{array}$ & $\begin{array}{c}\text { Inflação } \\
\text { (IPCA) }\end{array}$ & $\begin{array}{c}\text { Hiato do } \\
\text { produto }\end{array}$ & $\begin{array}{c}\Delta \% \text { prod. } \\
\text { industrial }\end{array}$ & $\begin{array}{c}\Delta \% \\
\text { Ibovespa }\end{array}$ \\
\hline $\mathrm{d} 1$ & 1 & 2 a 4 & 17,2 & 3,5 & 59,8 & 50,9 \\
$\mathrm{~d} 2$ & 2 & 4 a 8 & 19,2 & 8,0 & 20,3 & 23,8 \\
$\mathrm{~d} 3$ & 4 & 8 a 16 & 33,8 & 16,9 & 17,8 & 16,3 \\
$\mathrm{~d} 4$ & 8 & 16 a 32 & 25,4 & 41,4 & 1,9 & 7,8 \\
$\mathrm{~d} 5$ & 16 & 32 a 64 & 4,4 & 30,6 & 0,3 & 1,3 \\
\hline
\end{tabular}

variáveis ao longo das escalas com o respectivo limite inferior (L) e superior (U) do intervalo de confiança (95\%), vide equações (8) e (9) do Apêndice.

Da Figura 2, percebe-se que a inflação e o hiato do produto não se relacionam no curto, médio e longo prazos, diferente do resultado de Nunes et al. (2005) usando técnicas no domínio do tempo. Já o coeficiente de correlação entre a inflação e o retorno real do Ibovespa é mais elevado na escala 4, um pouco abaixo de 0,5 , contudo, o limite inferior do intervalo de confiança se aproxima de zero. De qualquer forma, isso contraria a evidência empírica de correlação negativa. A correlação entre o retorno real do Ibovespa e o hiato do produto torna-se mais negativa com o aumento da escala, porém, não é estatisticamente significativa. Ao contrário, quando a variável é a taxa de crescimento do produto industrial, a correlação com o retorno real do Ibovespa tende a ser positiva e aumenta com a escala, chegando ao valor máximo próximo de 0,8 . Outro ponto a notar é o aumento significativo do intervalo de confiança ao longo da escala, o que implica na imprecisão das estimativas obtidas.

Em resumo, do ponto de vista da simples relação contemporânea entre os diversos pares de variáveis, os resultados acima chamam atenção para uma análise mais robusta referente à relação inflação-hiato do produto (positiva e de curto prazo) presente na curva de Phillips, pois torna-se relevante para a política monetária se essa relação mais fraca é uma tendência de longo prazo ou um resultado casual. Todavia, este não é o objetivo do presente trabalho. Da mesma forma, supondo uma relação pró-cíclica entre o nível de atividade e o lucro das empresas, não se confirma a relação entre esse último e o retorno real das ações qualquer que seja a escala de comparação, mensal, bimestral, semestral, etc. Certamente, a análise precisa evoluir para verificar o comportamento das variáveis nas defasagens. Antes, porém, analisa-se a relação contemporânea entre grupos de variáveis.

De forma a aprofundar a análise, calcula-se a correlação múltipla wavelet, proposta por Fernández-Macho (2012). Para tanto, suponha que $\widetilde{d}_{j, t}^{i p c a}, \widetilde{d}_{j, t}^{y h}$ e $\widetilde{d}_{j, t}^{\text {ibov }}$ sejam os coeficientes wavelet da inflação, hiato do produto e retorno real do Ibovespa na escala $\lambda_{j}$, respectivamente. Assim, a correlação múltipla wavelet para a inflação, por exemplo, pode ser estimada por:

$$
\tilde{\varphi}_{i p c a}=\operatorname{Corr}\left(\widetilde{d}_{j, t}^{i p c a}, \widehat{\bar{d}_{j, t}^{i p c a}}\right),
$$

onde $\widehat{\vec{d}_{j, t}^{i p c a}}$ é o valor ajustado do coeficiente wavelet da inflação em uma re- 
Figura 2: Correlação wavelet: inflação, hiato, crescimento da produção industrial e retorno real do Ibovespa.
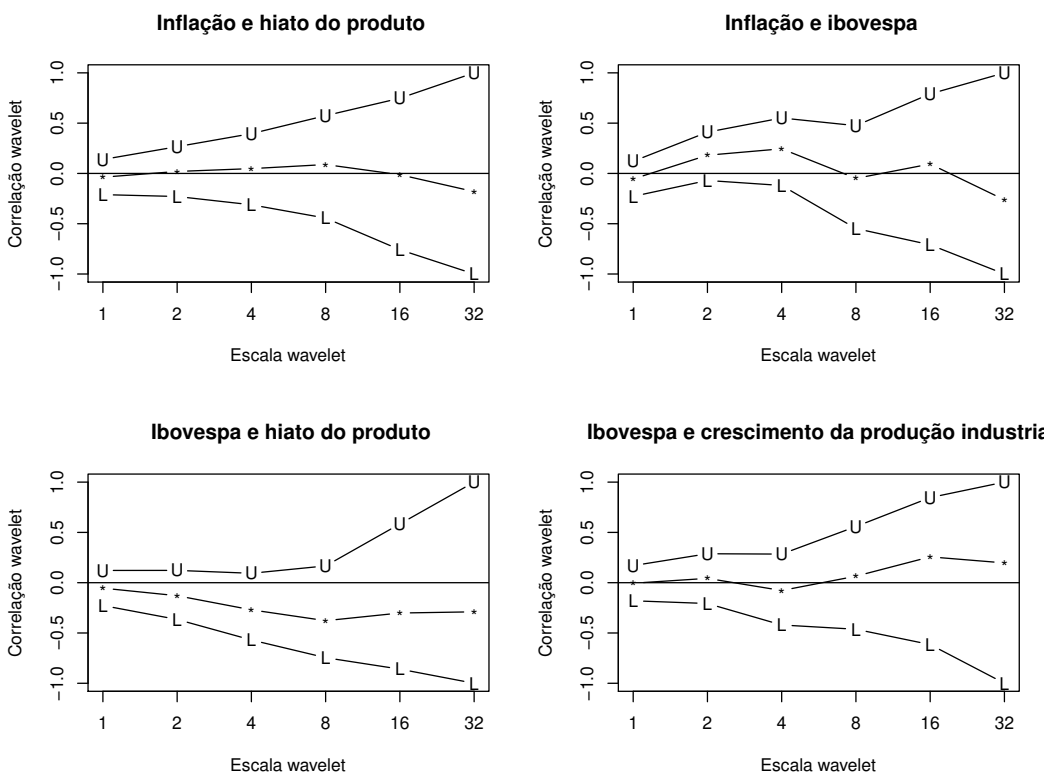

gressão tendo como variáveis explicativas os coeficientes do hiato do produto e do retorno real do Ibovespa. A variável explicada é devidamente identificada ao longo do eixo das abscissas nos gráficos da Figura 3. Nos 3 primeiros, as variáveis envolvidas são $\widetilde{d}_{j, t}^{i p c a}, \widetilde{d}_{j, t}^{y h}$ e $\widetilde{d}_{j, t}^{i b o v}$ e no último, identificado como $\Delta \log$ (pind) no eixo da abscissa, os coeficientes do hiato são trocados pelos da taxa de crescimento da produção industrial.

Em geral, levando em conta os intervalos de confiança, as correlações múltiplas obtidas não são estatisticamente significativas. A única exceção ocorre na regressão dos coeficientes wavelets do retorno do Ibovespa sobre os coeficientes da inflação e do hiato do produto. Na escala 4, o coeficiente de correlação múltipla wavelet é próximo de 0,5. Isso significa que nos ciclos entre 8 e 16 meses as flutuações da inflação e do hiato do produto ajudam a explicar a variabilidade do retorno real do Ibovespa. Como visto na Figura 2, isoladamente essas variáveis não apresentam correlações significativas com o Ibovespa.

Além de rejeitar a hipótese proxy, esses resultados iniciais mostram que a dinâmica do retorno de ações pode ser explicada, em uma determinada escala, pela combinação de inflação e atividade econômica. Nesse sentido, a implicação da hipótese de Fisher de que fatores reais explicariam os retornos reais independentemente da inflação não se sustenta de forma consistente.

Voltando à possibilidade de relações defasadas, nas Figuras 4, 5, 6 e 7 observa-se, respectivamente, a correlação cruzada wavelets (e os correspondentes intervalos de confiança, 95\%) entre a inflação no período $t$ e o hiato do produto no período $(t-v)$; a inflação e retorno real do Ibovespa; e deste último com o hiato do produto e a taxa de crescimento da produção industrial, respectivamente. A base de cálculo é a equação (11) do Apêndice, sendo todos com atrasos e adiantamentos de 36 meses, desagregada em seis níveis 
Figura 3: Correlação múltipla wavelet: inflação, retorno real do Ibovespa, hiato e crescimento da produção industrial.

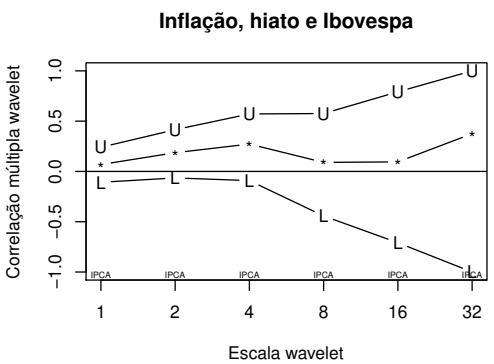

Hiato, inflação e lbovespa

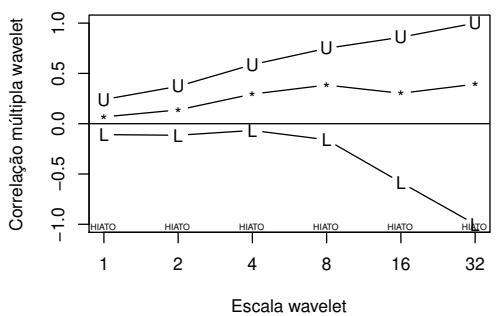

lbovespa, inflação e hiato

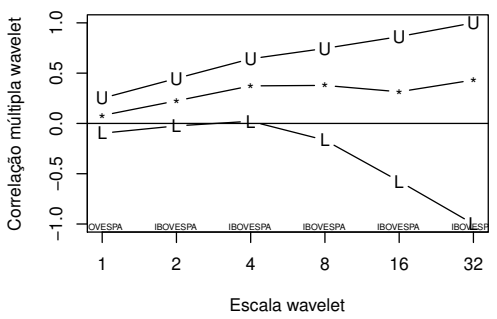

Produção industrial, inflação e lbovespa

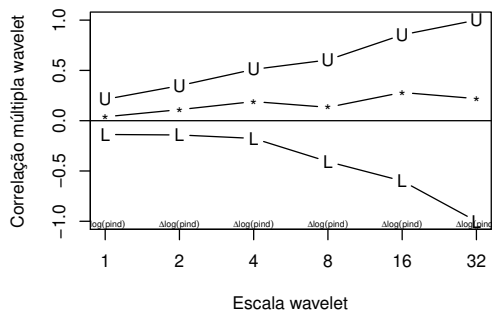

de decomposição. O intuito é capturar as relações nos ciclos de curto, médio e longo prazos entre pares de variáveis levando em conta as defasagens.

De modo geral, em todas as escalas, a magnitude da relação entre as variáveis é próxima de zero. Na Figura 6, porém, é possível identificar correlações cruzadas estatisticamente significativas nos níveis 3, 4 e 5. A correlação na defasagem em torno de 3 meses, nível 3, pode ser interpretada como a situação em que a componente cíclica do retorno do Ibovespa entre 8 e 16 meses responde às flutuações passadas do hiato do produto nesse mesmo ciclo. No nível 4 (1,3 a 2,7 anos) não é possível identificar se uma variável atua como um indicador antecedente em relação à outra. Nesse componente cíclico, o hiato do produto responde às flutuações do retorno real do Ibovespa com 9 meses de defasagem e as variações do hiato antecedem em 3 meses o movimento do retorno do Ibovespa. No nível 5, entre 3 e 5 anos, há uma resposta defasada e positiva de 1 ano, porém, o limite do intervalo de confiança é próximo de zero. Vale destacar da Figura 7 a correlação elevada da taxa de crescimento da produção industrial com os valores passados do retorno real do Ibovespa no nível 5, ou seja, nos ciclos entre 3 a 5 anos, aproximadamente. Contudo, a exemplo da Figura 2, essa medida é bastante imprecisa e chega a zero no limite do intervalo de confiança.

Portanto, a hipótese proxy não pode ser corroborada, ainda que haja um fraco link entre retorno real e atividade econômica.

Como complemento à Figura 3, essa subseção ainda apresenta a Figura 8, que também é baseada na equação (1). Entretanto, em cada escala $\lambda_{j}$ a variável dependente é aquela que maximiza a correlação múltipla wavelet, tal como definido em Fernández-Macho (2012). O nome dessa variável é devidamente identificado em cada escala da Figura 8. Nas escalas 1, 2 e 4 da Figura 8 (a), 
Figura 4: Correlação cruzada wavelet entre inflação e hiato do produto.
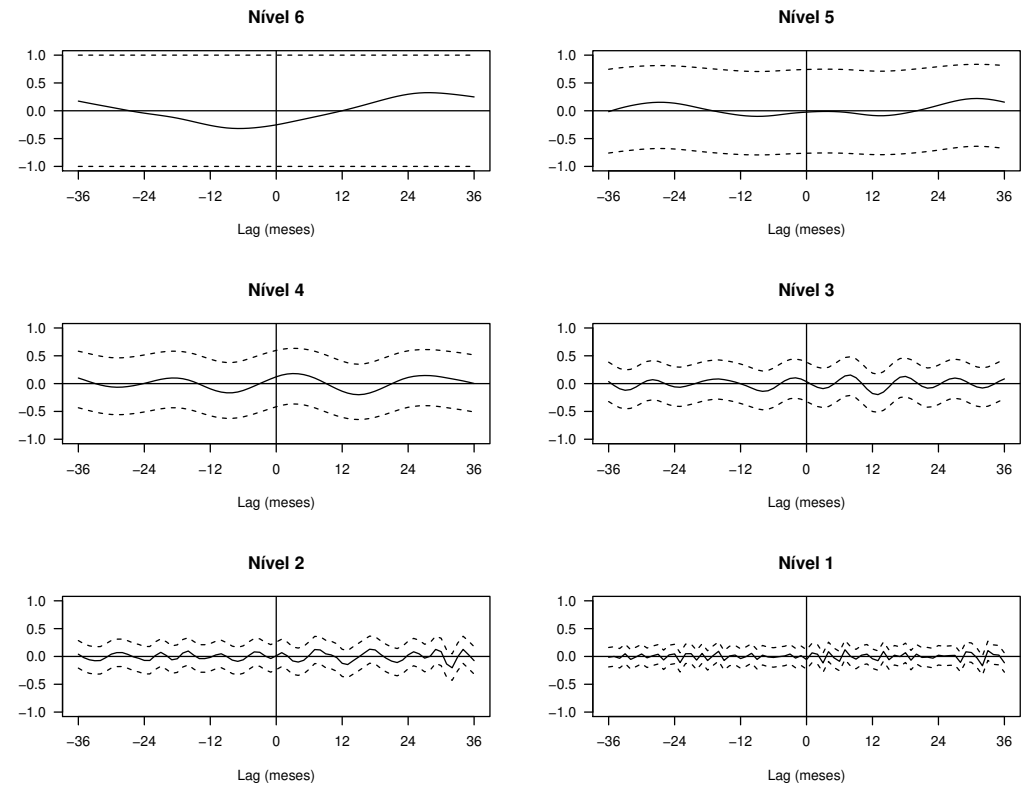

Figura 5: Correlação cruzada wavelet entre inflação e retorno real do Ibovespa.
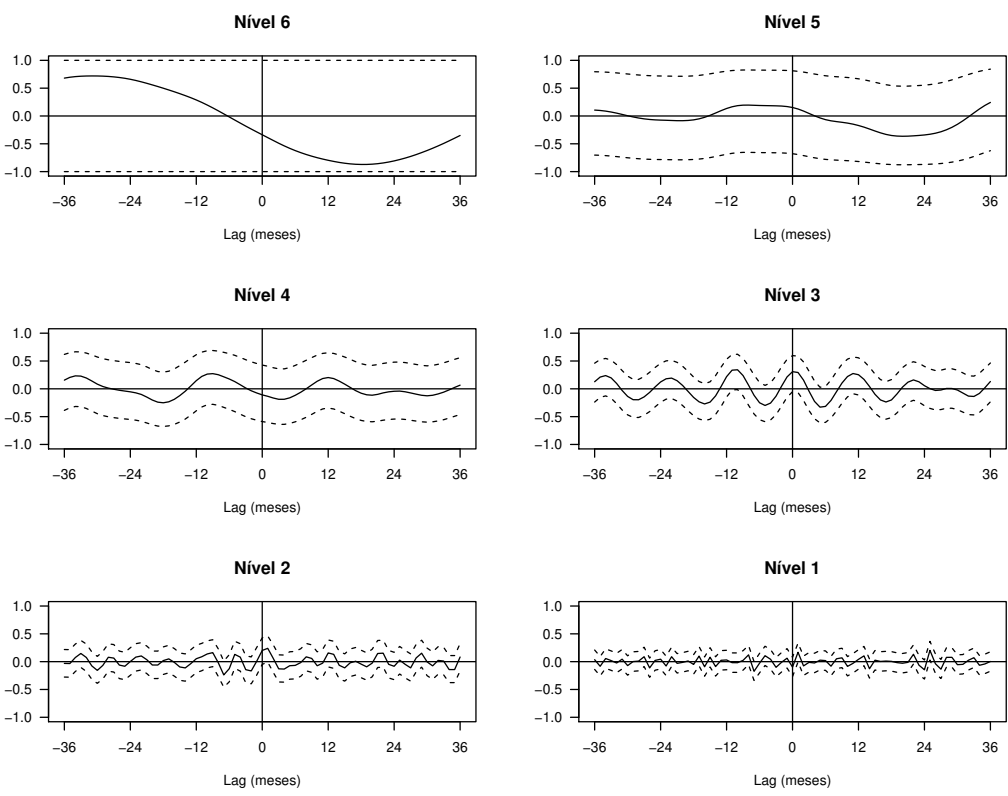
Figura 6: Correlação cruzada wavelet entre o retorno real do Ibovespa e hiato.
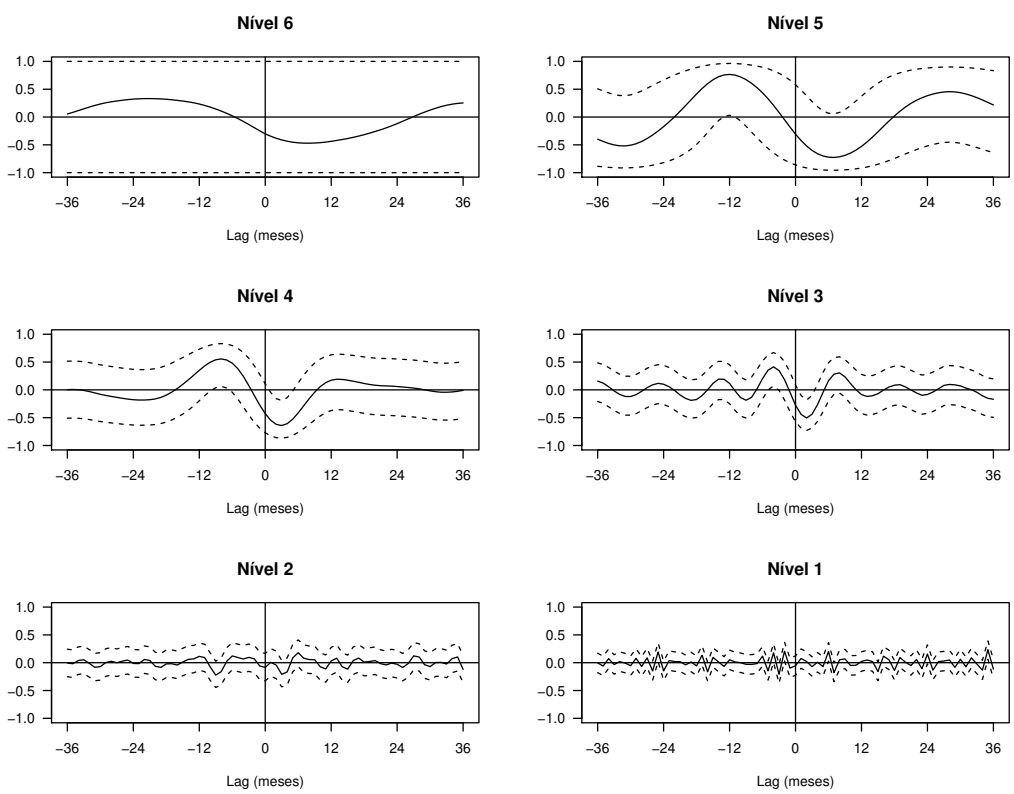

Figura 7: Correlação cruzada wavelet entre retorno o retorno real do Ibovespa e taxa de crescimento da produção industrial.
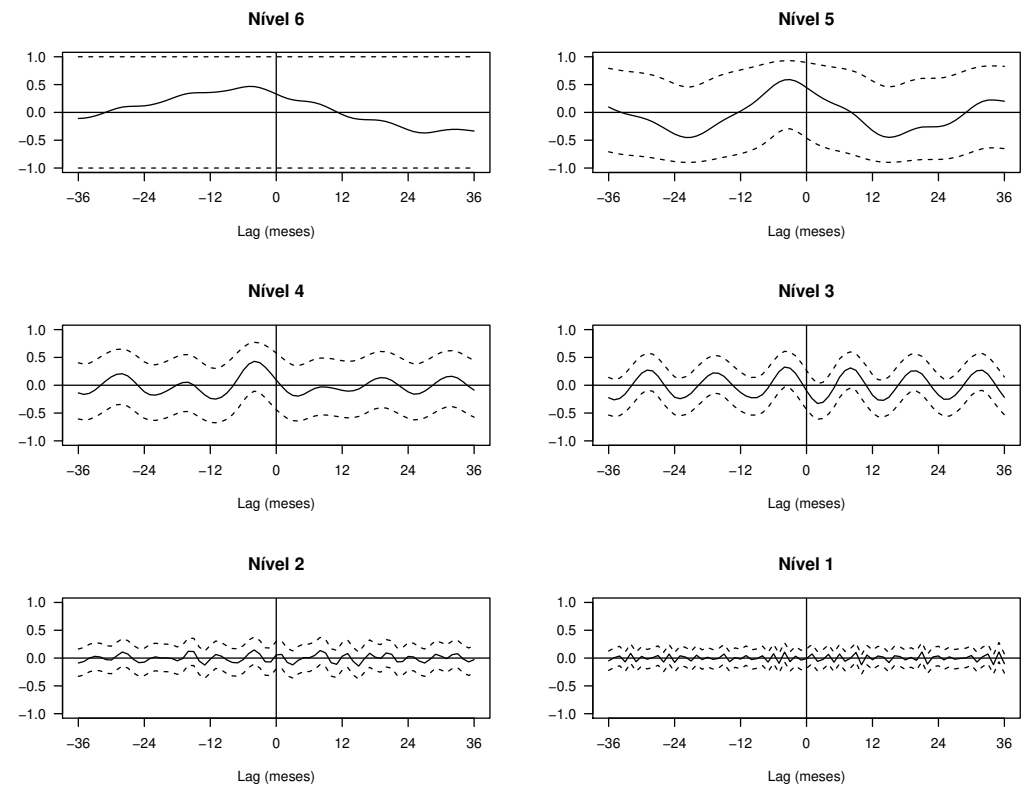
os coeficientes wavelets do retorno real do Ibovespa são regredidos contra os do hiato do produto e da inflação (ipca) em diversas defasagens. Na escala 8, o hiato do produto é a variável que maximiza a correlação múltipla. A correlação na escala 8 é a mais alta, havendo relações defasadas e adiantadas entre o hiato do produto e a combinação linear da inflação com o retorno real do Ibovespa. Quando o hiato é substituído pela taxa de crescimento da produção industrial, Figura 8 (b), há uma mudança geral nas variáveis maximizadoras da correlação em todas as escalas: a inflação (ipca) nas escalas 1, 2 e 4 e o Ibovespa na 8.

Fica aparente dessa análise que, ao contrário do caso contemporâneo, a inclusão da inflação não altera a correlação cruzada entre o retorno de ações e a atividade econômica, conforme se espera.

\subsection{Abordagem discreta: análise de multirresolução}

A chamada análise de multirresolução (MRA - Multi-Resolution Analysis) permite a decomposição aditiva da série, descrevendo suas variações em cada escala específica bem como seu componente de tendência. Isso é conseguido pela inversão da transformada wavelet (MODWT, por exemplo) em cada nível separadamente. Seguindo Constantine \& Percival (2016), a MRA implica que a série original $X$ possa ser escrita por $X=S_{J}+\sum_{j=1}^{J} D_{j}$, onde $D_{1}, \ldots, D_{J}$ expressa os detalhes e $S_{J}$ a parte suave. Cada $D_{j}$ é uma série temporal que descreve as variações de $X$ no intervalo de frequências $\left[\frac{1}{2^{j+1}}, \frac{1}{2^{j}}\right]$. $S_{J}$, por sua vez, é o componente suave mostrando as mudanças de $X$ na baixa frequência, $\left[0, \frac{1}{2^{J+1}}\right]$.

A Tabela 2 apresenta as regressões estimadas com as séries derivadas da análise MRA, onde encontram-se os coeficientes angulares $(\beta)$, as estatísticas t e os coeficiente de determinação $\left(R^{2}\right)$. Os valores $R^{2}$ estão quase sempre aumentando à medida que a escala de tempo aumenta dentro dos intervalos de curto, médio e longo prazos. Em D1 (ciclo de 2 a 4 meses), a relação entre o retorno nominal das ações e a inflação é significativamente negativa, o que implica que as ações nominais não estariam acompanhando a inflação de forma a se proteger desta última, mas em linha com a intrigante relação negativa apresentada na literatura. De forma a corroborar, em seguida, testa-se a relação entre retorno real e inflação de forma a verificar a habilidade do primeiro servir de hedge contra a inflação. O retorno real das ações também apresenta valor negativo do coeficiente angular. À medida que a escala de tempo aumenta, o coeficiente $\beta$ mostra um valor positivo em D2, D3, D5 e S7; e um valor negativo nos restantes (D4, D6 e D7). Tal comportamento é semelhante tanto em termos nominais quanto real, ou seja, contraditório. Quando agrega-se, os resultados nominais e reais novamente se parecem, revelando uma relação positiva e significativa no curto e longo prazos, enquanto a relação de médio prazo se mostra negativa mas não é estatisticamente significativa. De forma complementar, apresentam-se regressões do retorno real Ibovespa relativo à variação da produção industrial. Os resultados mostram que no curto prazo os coeficientes não são estatisticamente significativos, mas no médio e longo prazos são positivos e significativos, conforme esperado. De forma geral, a relação entre o retorno nominal de ações e inflação não difere muito da relação entre o retorno real de ações e inflação, dando destaque para a relação positiva observada tanto no curto quanto no longo prazos. Já o retorno real mostra 
Figura 8: Correlação cruzada wavelet: (a) inflação, retorno real do Ibovespa e hiato; e (b) inflação, retorno real do Ibovespa e taxa de crescimento da produção industrial.

(a)
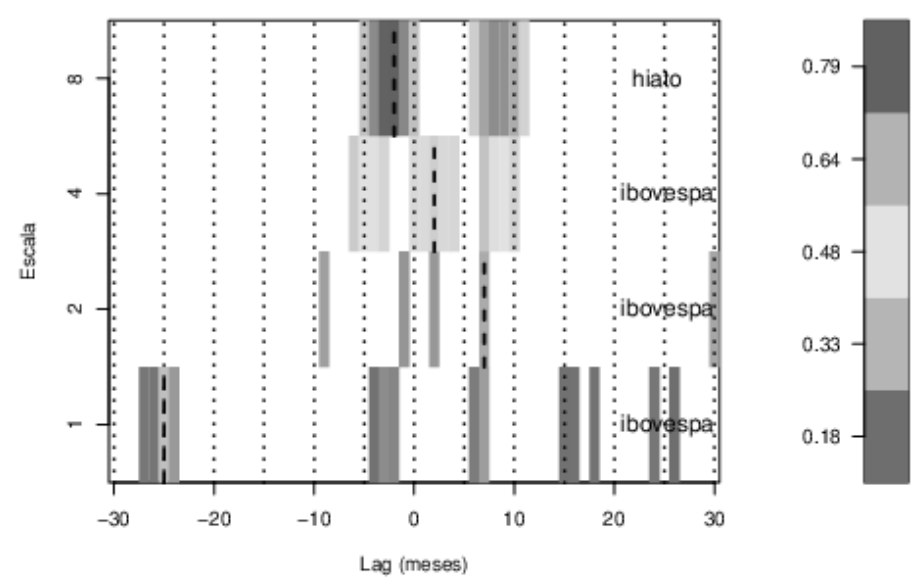

(b)
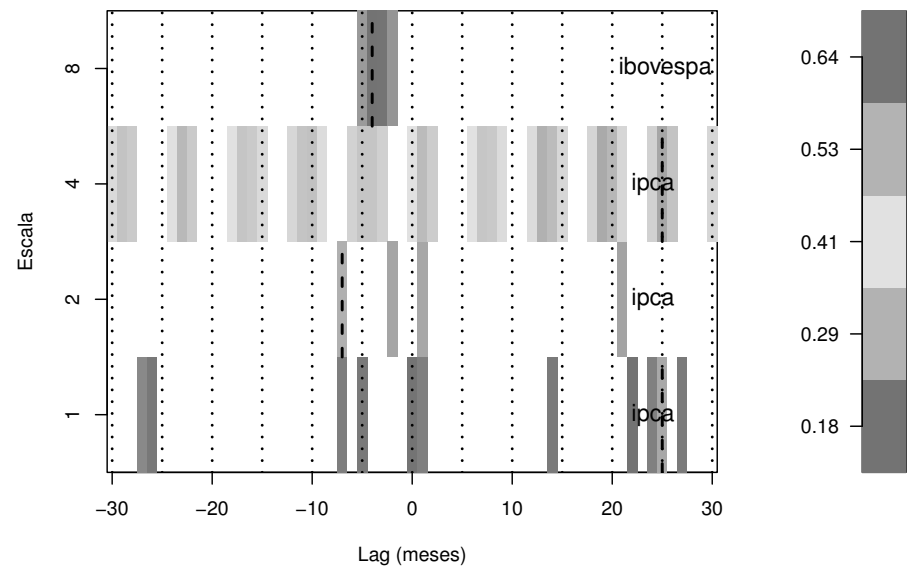
também se relacionar positivamente com a variação da produção no médio e longo prazos.

Tabela 2: Regressão no domínio wavelet

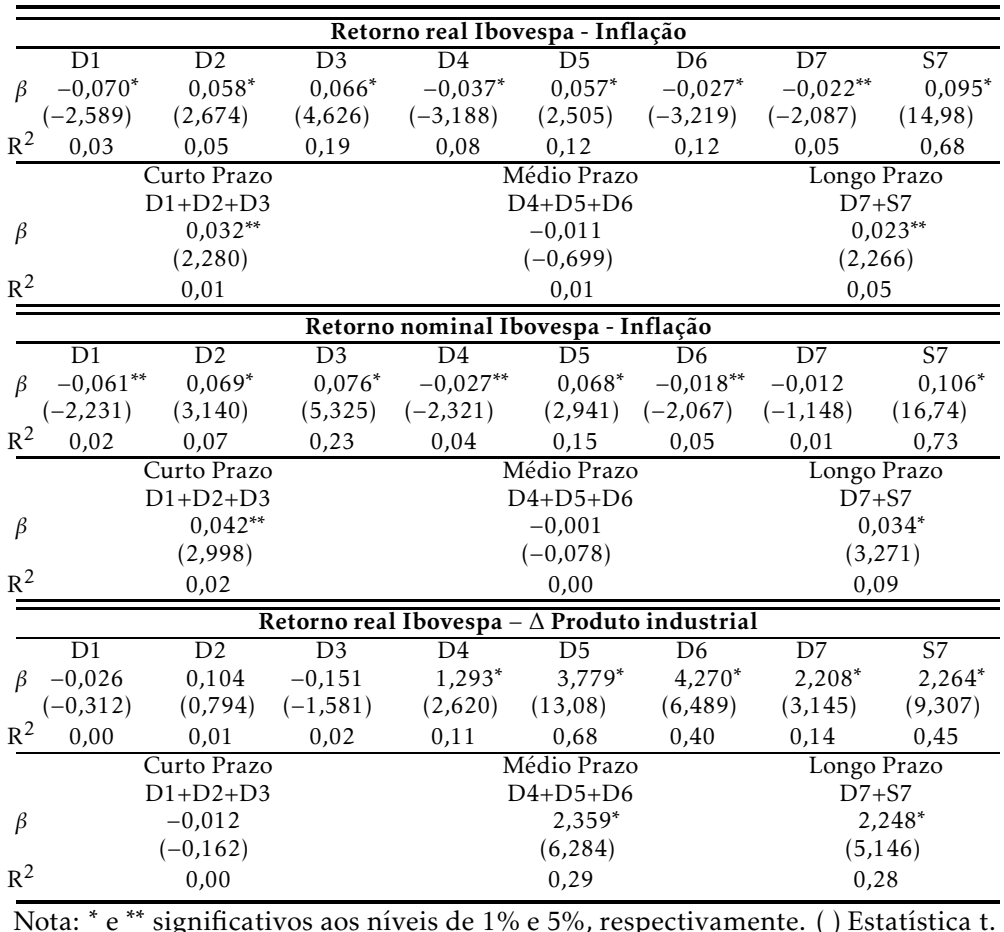

A Tabela 3 replica o exercício da Tabela 2 considerando a relação entre a inflação com o hiato do produto e, posteriormente, com a variação da produção. $\mathrm{Na}$ primeira relação, os valores $R^{2}$ estão aumentando à medida que a escala de tempo aumenta, mas apenas o longo prazo se mostra positivamente significativo. Esse resultado parece mostrar uma importante contradição com as correlações obtidas anteriormente. Contudo, deve-se relembrar que na transformada wavelet calculam-se implicitamente diferenças entre médias ponderadas. Portanto, nos níveis mais altos da transformada, as séries obtidas do procedimento de multirresolução são mais suaves, reduzindo a variabilidade amostral da variável explicativa e dependente. ${ }^{6}$ Adicionalmente, os níveis que contemplam os ciclos de longo prazo carregam mais coeficientes com problemas de borda. No caso do cálculo das correlações wavelets precedentes, o estimador da variância (covariância) é não enviesado, ou seja, controlam-se os coeficientes de borda e ajustam-se os graus de liberdade na determinação do intervalo de confiança. No que tange ao caso da relação entre a inflação e a taxa de variação da produção industrial, apenas em D3 e D6 obtém-se

\footnotetext{
${ }^{6}$ Os exercícios desta subseção têm como inspiração os trabalhos de Kim \& In (2005) e Gallegati et al. (2011). Uma análise mais rigorosa sobre a significância dos coeficientes e a possibilidade de inferência espúria, principalmente no longo prazo, requer um exame mais aprofundado, o que está além do escopo deste trabalho e poderia ser indicado como um tópico interessante para pesquisa futura (ver Lundberg (2015)). De todo modo, os resultados de curto e médio prazos aqui obtidos corroboram os achados anteriores e a contradição no longo prazo fortalece a recomendação de análises mais robustas referentes à relação inflação-hiato do produto.
} 
significância negativa, mas em nenhum dos prazos agregados tal resultado se mantém.

Logo, apesar de surgir alguns resultados conforme esperado, o mesmo não se mostram consistentes. Entretanto, pode-se observar a relevância de um comportamento heterogêneo ao longo do tempo e entre as escalas.

Tabela 3: Regressão no domínio wavelet

\begin{tabular}{|c|c|c|c|c|c|c|c|c|}
\hline \multicolumn{9}{|c|}{ Inflação - Hiato do produto } \\
\hline & $\overline{\mathrm{D} 1}$ & $\overline{\mathrm{D} 2}$ & $\overline{\mathrm{D} 3}$ & $\overline{\mathrm{D} 4}$ & $\overline{\mathrm{D} 5}$ & $\overline{\mathrm{D} 6}$ & $\overline{\mathrm{D} 7}$ & S7 \\
\hline$\beta$ & $-1,230$ & $-0,101$ & $-0,172$ & 1,758 & $-0,525$ & $-14,93^{*}$ & $82,08^{*}$ & $-129,7^{*}$ \\
\hline & $(-1,146)$ & $(-0,078)$ & $(-0,071)$ & $(1,798)$ & $(-0,732)$ & $(-5,667)$ & $(7,348)$ & $(-10,99)$ \\
\hline$R^{2}$ & 0,01 & 0,00 & 0,00 & 0,03 & 0,01 & 0,21 & 0,42 & 0,56 \\
\hline & \multirow{2}{*}{\multicolumn{3}{|c|}{ Curto Prazo }} & \multirow{2}{*}{\multicolumn{3}{|c|}{ Médio Prazo }} & \multicolumn{2}{|c|}{ Longo Prazo } \\
\hline \multirow{3}{*}{$\beta$} & & & & \multirow{2}{*}{\multicolumn{3}{|c|}{ D4+D5+D6 }} & \multicolumn{2}{|c|}{$\mathrm{D} 7+\mathrm{S} 7$} \\
\hline & & \multirow{2}{*}{\multicolumn{2}{|c|}{$\begin{array}{l}-0,250 \\
(-0,187)\end{array}$}} & \multirow{2}{*}{\multicolumn{3}{|c|}{$(0,318)$}} & \multirow{2}{*}{\multicolumn{2}{|c|}{$\begin{array}{l}28,16^{* *} \\
(2,180)\end{array}$}} \\
\hline & & & & & & & & \\
\hline$R^{2}$ & \multicolumn{3}{|c|}{0,00} & \multicolumn{3}{|c|}{0,00} & \multicolumn{2}{|c|}{0,04} \\
\hline \multicolumn{9}{|c|}{ Inflação - $\Delta$ Produto industrial } \\
\hline & $\overline{\mathrm{D} 1}$ & $\overline{\mathrm{D} 2}$ & $\overline{\mathrm{D} 3}$ & $\overline{\mathrm{D} 4}$ & D5 & D6 & $\bar{D} 7$ & S7 \\
\hline \multirow[t]{2}{*}{$\beta$} & 0,225 & $-0,521$ & $-1,824^{*}$ & $-3,950$ & 1,933 & $-26,72^{*}$ & $-10,49$ & 4,161 \\
\hline & $(1,193)$ & $(-1,191)$ & $(-3,008)$ & $(-1,021)$ & $(0,573)$ & $(-3,810)$ & $(-1,574)$ & $(1,436)$ \\
\hline \multirow[t]{3}{*}{$\mathrm{R}^{2}$} & 0,01 & 0,01 & 0,07 & 0,02 & 0,00 & 0,10 & 0,03 & 0,02 \\
\hline & & \multirow{2}{*}{\multicolumn{2}{|c|}{ Curto Prazo }} & \multicolumn{3}{|c|}{ Médio Prazo } & \multicolumn{2}{|c|}{ Longo Prazo } \\
\hline & & & & & $\mathrm{D} 4+\mathrm{D} 5+\mathrm{L}$ & & & $+\mathrm{S} 7$ \\
\hline \multirow[t]{2}{*}{$\beta$} & & \multirow{2}{*}{\multicolumn{2}{|c|}{$\begin{array}{c}-0,282 \\
(-1,149)\end{array}$}} & \multirow{2}{*}{\multicolumn{3}{|c|}{$\begin{array}{c}-2,745 \\
(-0,602)\end{array}$}} & \multicolumn{2}{|c|}{$-0,145$} \\
\hline & & & & & & & & 031) \\
\hline$R^{2}$ & & \multicolumn{2}{|l|}{0,00} & \multicolumn{3}{|c|}{0,01} & \multicolumn{2}{|c|}{0,00} \\
\hline
\end{tabular}

\subsection{Abordagem discreta: digressão sobre o hiato}

Uma questão importante é a sensibilidade dos resultados em relação às medidas do hiato. Existem várias formas de se obtê-lo, como pode ser visto em, por exemplo, Gentil \& Messenberg (2009). Neste artigo, consistente com a metodologia empregada, o hiato é derivado através da metologia wavelet.

Os coeficientes wavelets permitem a reconstrução perfeita da série por meio do processo da transformada inversa. No entanto, assumindo a hipótese de que a série observada é composta por um sinal mais ruído, a transformada wavelet pode requerer uma quantidade bem menor de coeficientes para isolar as propriedades do sinal (determinista ou estocástico). Essa suposição leva à ideia de aplicar à transformada diferentes funções e níveis de limiares (threshold) tal que a regra reduza a zero alguns coeficientes. Outro procedimento é determinar a própria regra de encolhimento (shrinkage) por diversos métodos, como a formulação bayesiana, que consiste na estimação simultânea do nível e da função de encolhimento através da regra de Bayes. Esse é o esquema de referência adotado neste trabalho.

A estimação do sinal através da abordagem threshold ou shrinkage percorre as seguintes etapas: a) cálculo dos coeficientes wavelets; b) aplicação da regra de limiar ou encolhimento nos coeficientes e; c) estimação do sinal através da transformada inversa usando os coeficientes obtidos no passo anterior.

Na formulação bayesiana de Johnstone \& Silverman (2005a), cada coeficiente wavelet $(\mathrm{d})$ assume valor zero com probabilidade $(1-\omega)$ e a parte não nula da prior é proveniente de uma densidade simétrica de cauda pesada (heavytailed) $\gamma$ com probabilidade $\omega$. Essa mistura significa que a prior pode ser escrita como: 


$$
f_{\text {prior }}(d)=\omega \gamma(d)+(1-\omega) \delta_{0}(d)
$$

onde $\delta_{0}$ representa uma função de probabilidade com massa concentrada no ponto zero. Essa especificação captura a característica esparsa dos coeficientes wavelets: a maioria sendo zero, como pode ser notado na Figura 1.

A densidade marginal do coeficiente observado $\left(d^{*}\right)$ é dada por:

$$
\omega g\left(d^{*}\right)+(1-\omega) \phi\left(d^{*}\right)
$$

onde $g$ é a densidade obtida da convolução de $\gamma$ com a densidade normal padrão $\phi$, sendo a distribuição condicional de $d^{*}$ dada por $\left[d^{*} \mid d \sim \mathcal{N}\left(d, \sigma^{2}\right)\right]$.

O parâmetro $\omega$ é escolhido automaticamente através da estimativa de máxima verossimilhança marginal dos coeficientes observados $\left(d^{*}\right)$ e substituído de volta no modelo bayesiano. O estimador $\hat{\omega} \operatorname{de} \omega$, é obtido pela maximização de:

$$
l\left(\omega_{j}\right)=\sum_{t} \log \left\{\omega_{j} g\left(d_{j, t}^{*}\right)+\left(1-\omega_{j}\right) \phi\left(d_{j, t}^{*}\right)\right\}
$$

sendo possível estimar o parâmetro $\hat{\omega}_{j}$ para cada escala.

A implementação do método foi feita pelo pacote EbayesThresh (Silverman (2012)) da plataforma R, explicado em Johnstone \& Silverman (2005b). A rotina aplicada foi a básica, o que significa usar como prior para a densidade $\gamma(d)$ a distribuição de Laplace (exponencial dupla) dada por $\frac{1}{2} a e^{-a|\gamma(d)|}$, $\operatorname{com} a=0,5$. Alternativamente, o modelo foi especificado de forma que o parâmetro $a$ também seja uma estimativa obtida dos dados, ver Johnstone \& Silverman (2005a). O valor do desvio padrão $\sigma_{j}$ é a mediana dos desvios absolutos dos coeficientes em relação a zero em cada escala, sendo esses coeficientes estimados por MODWT usando o filtro $\mathrm{LA}(8)$ e $J=4$. A Tabela 4 contém as estimativas dos parâmetros do modelo.

No modelo 1 da Tabela 4 o valor de $a$ é determinado como sendo igual a 0,5 , enquanto no modelo 2 é estimado de acordo com os dados. A estimação de $a$, em vez do valor predeterminado, implica a redução de $\omega$, a proporção dos coeficientes não nulos, e o aumento do limiar (threshold), o que resulta em uma série mais suave quando reconstruída. Nos dois modelos, o número de coeficientes não nulos aumenta de acordo com a escala (nível), o que era esperado uma vez que o ruído tende a se concentrar nas escalas mais finas.

Como se observa na Figura 9, o hiato estimado através do método de limiarização de Johnstone \& Silverman (2005a) é um pouco mais atenuado que o computado pelo filtro HP, como em 1990 e 2008, por exemplo. Entretanto, a Figura 10 (a) mostra que isso não causa impacto em termos da forma como essa variável se correlaciona com a inflação, tal como visto na Figura 4. Por outro lado, a correlação do hiato com o retorno real do Ibovespa se altera. As relações observadas nos níveis 4 e 5 na Figura 6 perdem significância na Figura 10 (b). Somente a associação nos ciclos de 8 a 16 meses (nível 3) é estatisticamente significativa. Isso faz sentido na medida em que o filtro wavelet atribuiu maior peso aos ciclos de curto prazo na construção do hiato, reduzindo a importância do longo prazo. A mensagem é que o modo como o retorno real e 
Figura 9: Estimativa wavelet da produção industrial e hiato: (a) produção industrial dessazonalizada observada, wavelet e hp; e (b) estimativa do hiato wavelet e hp.

(a)

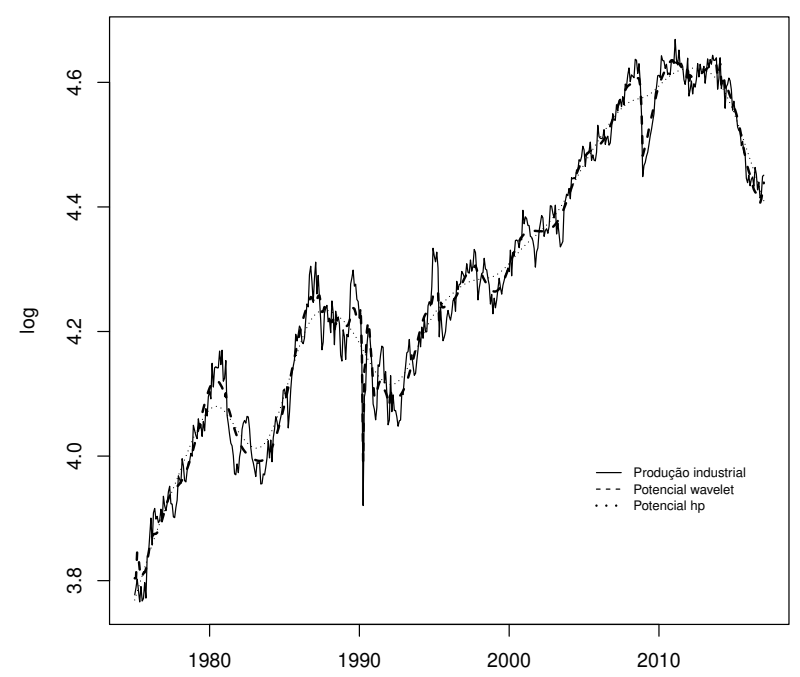

(b)

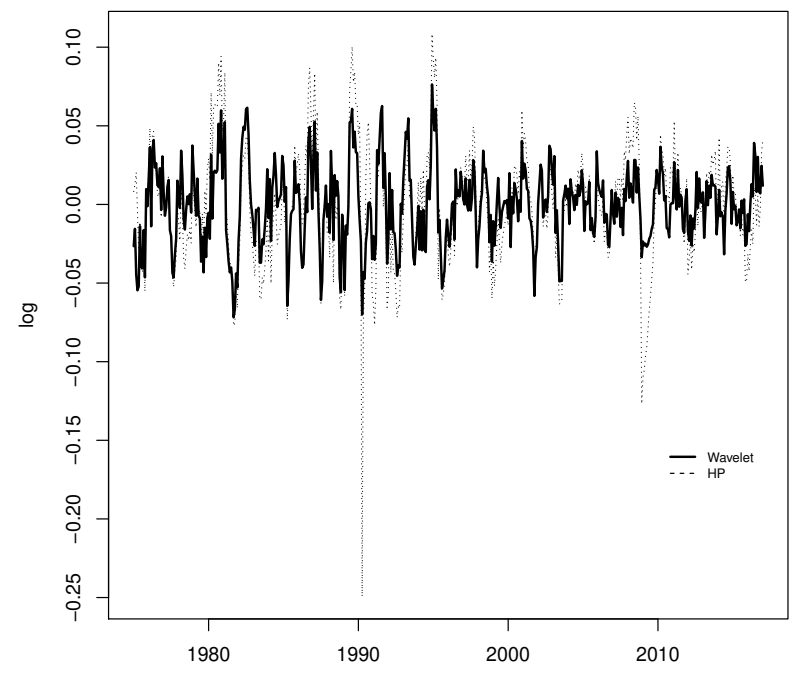


Tabela 4: Estimativas dos parâmetros do modelo bayesiano

\begin{tabular}{lcccc}
\hline \multirow{2}{*}{ Parâmetros } & \multicolumn{4}{c}{ Nível } \\
\cline { 2 - 5 } & $\mathbf{1}$ & 2 & $\mathbf{3}$ & 4 \\
\hline Modelo 1 & & & & \\
$\omega$ & 0,500 & 0,500 & 0,500 & 0,500 \\
$\sigma$ & 0,109 & 0,146 & 0,158 & 0,180 \\
Limiar (múltiplo de $\sigma_{j}$ ) & 0,704 & 0,657 & 1,039 & 1,444 \\
& 2,776 & 2,628 & 2,585 & 2,512 \\
Modelo 2 & & & & \\
$a$ & 0,338 & 0,291 & 0,377 & 0,396 \\
$\omega$ & 0,073 & 0,09 & 0,124 & 0,146 \\
$\sigma$ (igual ao modelo 1) & 0,704 & 0,657 & 1,039 & 1,444 \\
Limiar (múltiplo de $\sigma_{j}$ ) & 2,949 & 2,874 & 2,711 & 2,629 \\
\hline
\end{tabular}

a atividade econômica se relacionam nas diferentes escalas depende da forma de medida do hiato.

\subsection{Abordagem Contínua}

A versão contínua da análise wavelet possibilita uma visualização melhor e complementar dos resultados em relação à evolução da variância da inflação, hiato do produto, retorno real do Ibovespa e taxa de crescimento da produção industrial nas diferentes escalas de tempo. Além disso, serve como um meio de testar a robustez dos resultados obtidos na versão discreta, pois os filtros aplicados são diferentes.

Na Figura 11, mostram-se os respectivos espectros de potência wavelets para o período $1996 \mathrm{~m} 01$ a $2017 \mathrm{~m} 01$, calculados com base na equação (14) do Apêndice. Esse espectro permite inferir o quanto uma determinada frequência contribui para a variância da série em cada ponto do tempo. $\mathrm{O}$ eixo da ordenada representa o período do ciclo. Quanto mais acima nesse eixo, maior o período e menor a frequência. Por outro lado, em períodos menores a frequência é mais alta, indicando ciclos mais frenéticos. As áreas mais escuras do gráfico representam as regiões de maior volatilidade na série, e as mais claras o caso contrário. As linhas brancas de contorno limitam as regiões de significância ao nível de $5 \%$. A região externa ao desenho de um cone é a área sujeita a efeitos de borda e, portanto, onde as estatísticas devem ser interpretadas com cautela.

A Figura 11 (a) sugere que de 1996 a 2004, período pós-Plano Real até segundo ano do governo Lula, a variabilidade da inflação foi determinada por ciclos estatisticamente significativos quando comparados ao espectro de um processo $\mathrm{AR}(1)$ de alta frequência (inferiores a 1 ano). Entre 2002 e 2004, os ciclos de período de 1 a 2 anos também se tornaram estatisticamente importantes. De 2005 a 2010, a volatilidade em todas as frequências diminuiu, caracterizando um período de moderação na variabilidade da inflação. A partir de então, a variância da série aumentou novamente, se concentrando em ciclos de frequência anual, principalmente em 2014 e 2015. Explicações possí- 
Figura 10: Correlação cruzada do hiato calculado através da metodologia wavelet com: (a) inflação; e (b) retorno real do Ibovespa.

(a)
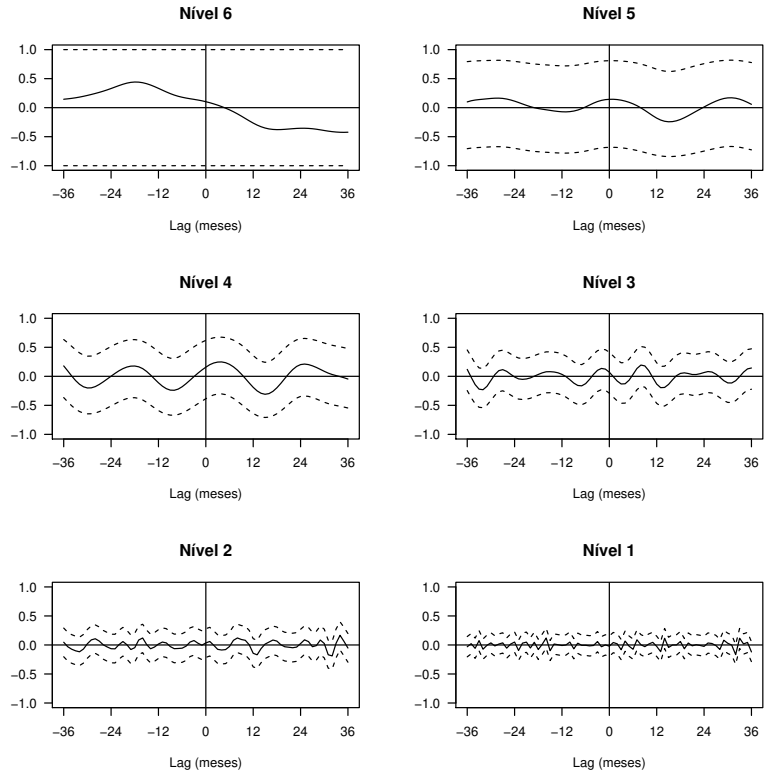

(b)
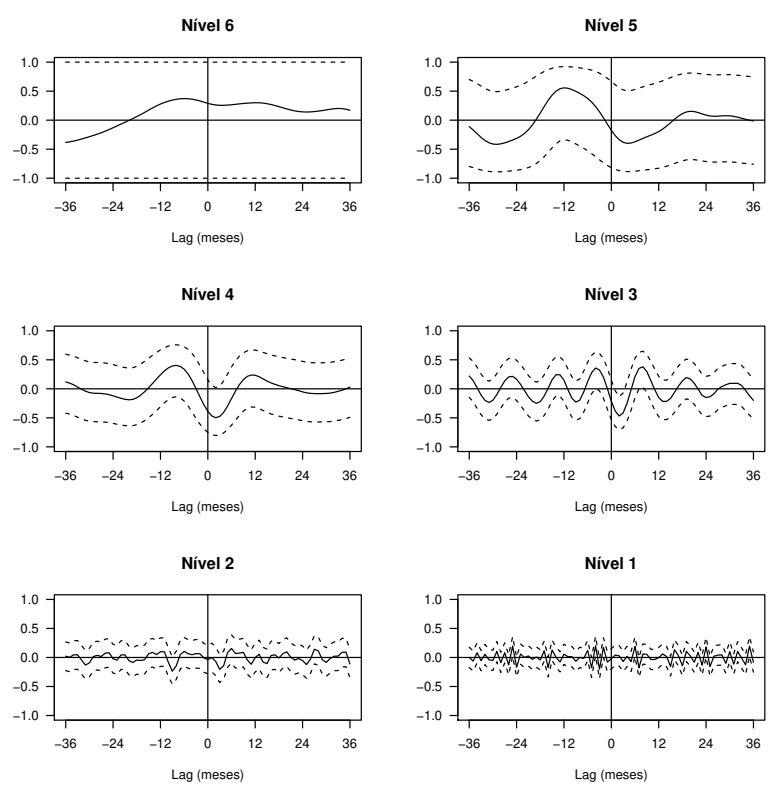
Figura 11: Espectro wavelet: (a) inflação; (b) hiato; (c) taxa de crescimento da produção industrial; e (d) retorno do Ibovespa.

(a)
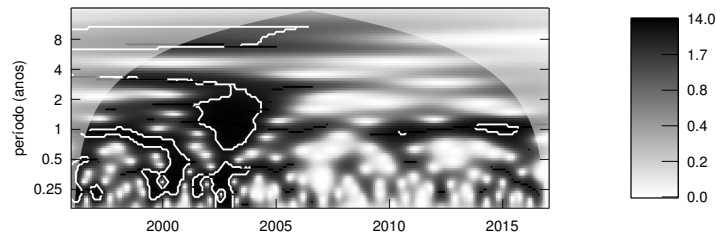

(b)
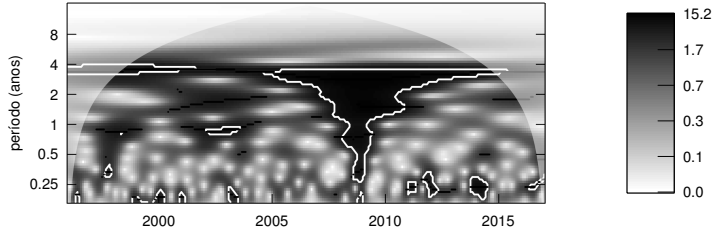

(c)
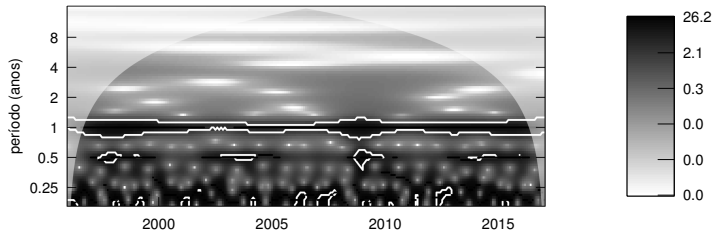

(d)
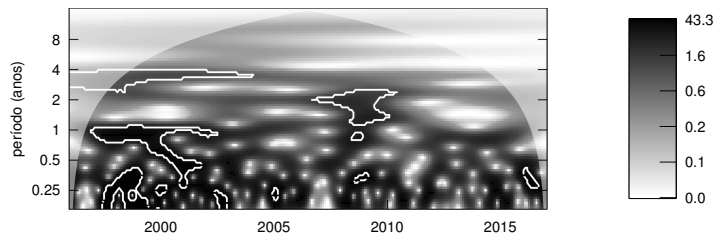
veis para esses resultados podem estar relacionadas à manutenção da política macroeconômica na transição de governo no início dos anos 2000 e ao comportamento dos preços administrados. ${ }^{7}$

Durante todo o período considerado, o espectro wavelet do hiato do produto da Figura 11 (b) contém alta potência no ciclo de negócios, tal como definido anteriormente. De 2008 a 2012, coincidentemente com o início da crise financeira internacional, os ciclos de curto prazo também se manifestaram importantes na variabilidade da série. Essa volatilidade de curto prazo também esteve presente em 1998 e 2003, onde observa-se a crise cambial de 1998 e os efeitos da crise de confiança na economia brasileira de 2002.

Na Figura 11 (c), é notável a presença de ciclos de altíssima frequência, inferiores a 4 meses, e o ciclo anual da taxa de variação da produção industrial. Eventualmente, ocorrem flutuações semestrais significativas, espaçadas com certa regularidade, como em 1997, 2003, 2008 e 2014-2015. O formato relativamente padronizado do espectro sugere que, do ponto de vista da análise wavelet, a volatilidade da produção industrial não apresenta picos ao longo do tempo, o que poderia se supor diante da maior exposição aos choques a que o produto poderia estar submetido em decorrência do processo de abertura comercial que se iniciou nos anos 1990.

Em consonância com a evidência encontrada na análise discreta, o espectro do retorno real do Ibovespa desenhado na Figura 11 (d) é bastante caracterizado por ciclos de curto prazo, destacando-se o horizonte 1998-2003. É possível identificar ciclos na frequência acima de 1 ano entre 2008 e 2010. Entre 2010 e 2014 há certa moderação na variabilidade cíclica de curto prazo.

Na Figura 12 se observa a coerência e a diferença de fase entre pares de variáveis (vide equações (16) e (18) do Apêndice), o que permite estudar o sincronismo entre elas. Pode-se perceber a evolução temporal entre as escalas ou períodos de tempo medidos em meses. As regiões estatisticamente significativas são delimitadas por linhas brancas e preenchidas com setas, que indicam a diferença de fase entre as variáveis. A direção e a rotação das setas determinam, respectivamente, o sinal e a antecedência da relação, como pode ser consultado em Aguiar \& Soares (2011). Por exemplo, as setas voltadas para a direita e para baixo na Figura 12 (a) informam que a inflação e o hiato do produto são positivamente correlacionados, com o ciclo do hiato antecedendo ao da inflação. Valores baixos de coerência são indicados pelas áreas mais claras do gráfico e os mais altos pelas mais escuras. O cone de influência separa o plano em regiões onde as estatísticas são mais confiáveis.

Antes de 2000, a inflação e o hiato do produto flutuavam em fases opostas, com o hiato sendo a variável a se mover primeiro. Essa observação é estatisticamente válida para o período associado ao ciclo anual. Houve mudança na frequência do ciclo e no sincronismo da relação entre as duas séries no intervalo próximo a 2002-2005, no qual o ciclo do hiato antecedia ao da inflação, agora na frequência próxima a dois anos. A partir de então, regiões de alta coerência, estatisticamente significativas, são escassas, levando a uma fraca ligação entre inflação e hiato do produto. Portanto, a análise contínua revela um detalhe adicional em relação à discreta: ainda que essa relação não seja expressiva na amostra como um todo, ela varia ao longo do tempo e já foi mais

\footnotetext{
${ }^{7}$ A transformada MODWT dos preços monitorados, não reportada, indica que até 2007 havia a presença de ciclos nas escalas 1, 2, 4 e 8. A partir de então, esses preços tornam-se estáveis, voltando em 2015, aproximadamente, a conter flutuações nas escalas de curto prazo.
} 
Figura 12: Coerência wavelet: (a) inflação e hiato; (b) inflação e retorno do Ibovespa; (c) retorno do Ibovespa e hiato; e (d) retorno do Ibovespa e taxa de crescimento da produção industrial.

(a)
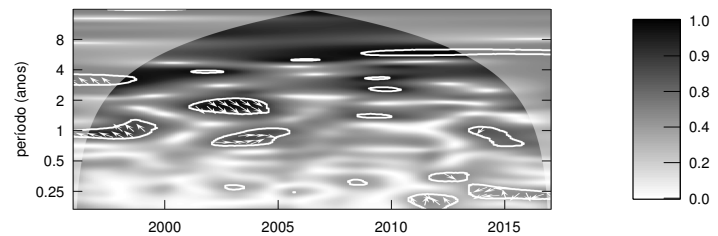

(b)
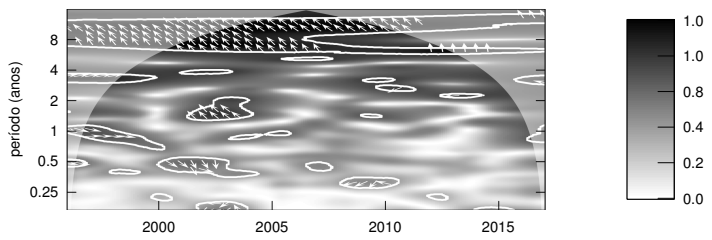

(c)
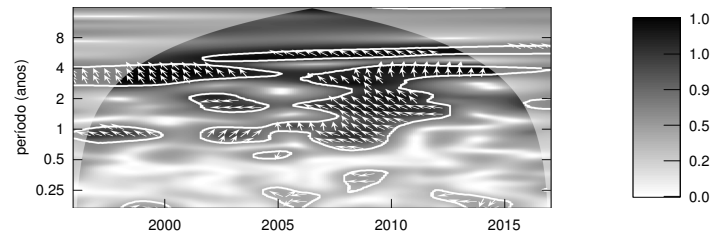

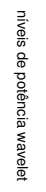

(d)
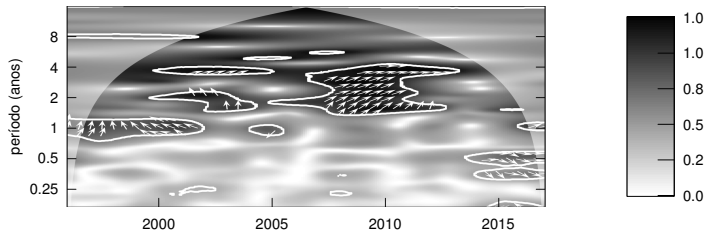
forte no passado, o que está de acordo com a observação de Blanchard et al. (2016) apresentada ao final desta subseção.

Já a coerência entre o retorno do Ibovespa e a inflação, Figura 12 (b), é relativamente baixa, com alguma relevância entre 2002 e 2004.

Por outro lado, a coerência entre o retorno do Ibovespa e o hiato, Figura 12 (c), é mais bem estabelecida. Há uma associação entre os ciclos de período superior a quatro anos durante praticamente todo o período de análise. $\mathrm{O}$ impacto da crise financeira internacional também pode ser percebido. Entre 2008 e 2010, há um espalhamento das regiões de alta coerência no ciclo de 4 anos em direção aos de até 1 ano, com menor magnitude entre 2 e 3 anos, aproximadamente. Ainda analisando esse período, as flechas da figura levam a concluir que as duas variáveis flutuavam em fase opostas nos ciclos de até 2 anos, movendo-se primeiro o hiato. Ao nível de atividade acima do potencial em um determinado período advinha à redução no retorno do Ibovespa. Nos ciclos vizinhos a 4 anos a fase muda, com alternância na variável antecedente. A Figura 12 (c) permite concluir que as correlações observadas na Figura 6 são influenciadas pelos eventos entre 2008 e 2012.

O cálculo da coerência no caso retorno do Ibovespa versus a taxa de crescimento da produção industrial é marcado por valores altos em torno do quadriênio 2008-2012 nos ciclos entre 2 a 4 anos, Figura 12 (d). As variáveis são positivamente correlacionadas. Isso sugere que nesse período e nesse horizonte cíclico o aumento (redução) do retorno real do Ibovespa precede ao acréscimo (decréscimo) da produção industrial. Nota-se que a região de alta coerência é um pouco distinta da observada no caso do hiato. Note que essa análise confirma e complementa o observado na Figura 7. Ratifica que os ciclos relevantes são superiores a 2 anos (nível 5 da Figura 7) e suplementa no sentido de estabelecer onde exatamente essa relação se torna mais forte, 2008-2012.

Na Figura 13, coloca-se lado a lado a coerência total e parcial wavelet entre as variáveis, seguindo Aguiar \& Soares (2011). Essa abordagem é uma extensão ao conceito de coerência, análoga à diferença entre a noção de correlação simples e parcial no domínio do tempo. A ideia é verificar a relação entre duas variáveis controlando o efeito de uma terceira, que eventualmente compartilha de um mesmo ciclo com as outras duas. Na Figura 13 (a), à esquerda, calcula-se a coerência entre a inflação e o hiato e, à direita, a coerência parcial entre essas mesmas variáveis após controlar os ciclos comuns do retorno real do Ibovespa. O painel (b) destaca a relação entre a inflação e o retorno real do Ibovespa, sendo o hiato a variável a ser controlado no painel à direita. Em (c) avalia-se o retorno real do Ibovespa e o hiato, controlando a inflação; e em (d) o hiato é substituído pela taxa de crescimento do produto industrial. ${ }^{8}$

Os resultados mostrados na Figura 13 (a) e (b) não mudam a percepção da forma como a inflação se relaciona com o hiato e o retorno real do Ibovespa, respectivamente. Por outro lado, o cálculo da coerência parcial altera a interpretação da ligação cíclica do retorno do Ibovespa com o hiato e a taxa de variação da produção industrial, (c) e (d). A relação de curto prazo, observada em torno de 2008, entre o retorno do Ibovespa e o hiato do produto, lado esquerdo de (c), fica mais restrita ao curtíssimo prazo ao se calcular a coerência parcial, ao passo que o ciclo acima de 3 anos se estende de 1996 até

\footnotetext{
${ }^{8}$ Ao contrário das figuras anteriores desta Seção, nesse caso particular da Figura 13, as áreas mais escuras do gráfico representam as regiões de menor volatilidade na série e as mais claras o caso contrário. Igualmente, valores baixos de coerência são indicados pelas áreas mais escuras do gráfico e os mais altos pelas mais claras.
} 
2008. No caso da taxa de crescimento da produção industrial e o retorno do Ibovespa, o cálculo da coerência parcial faz surgir alguma relação nos ciclos de alta frequência e torna mais ampla a relação entre essas variáveis no ciclo de 3 anos.

Figura 13: Coerência e coerência parcial wavelet: (a) inflação e hiato; (b) inflação e retorno real do Ibovespa; (c) retorno real do Ibovespa e hiato; e (d) retorno real do Ibovespa e taxa de crescimento da produção industrial.

(a)
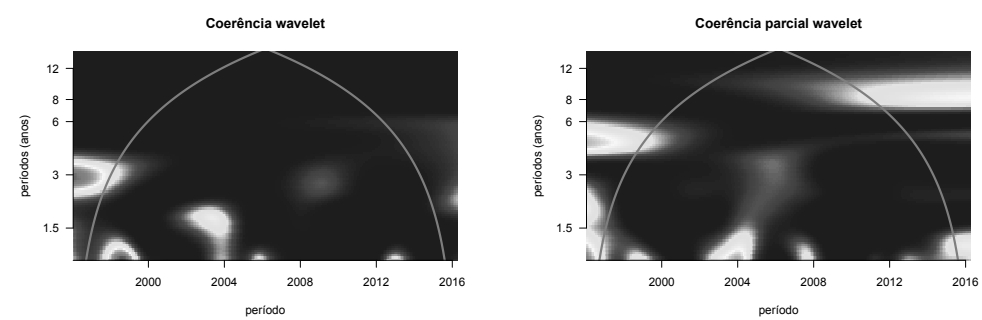

(b)
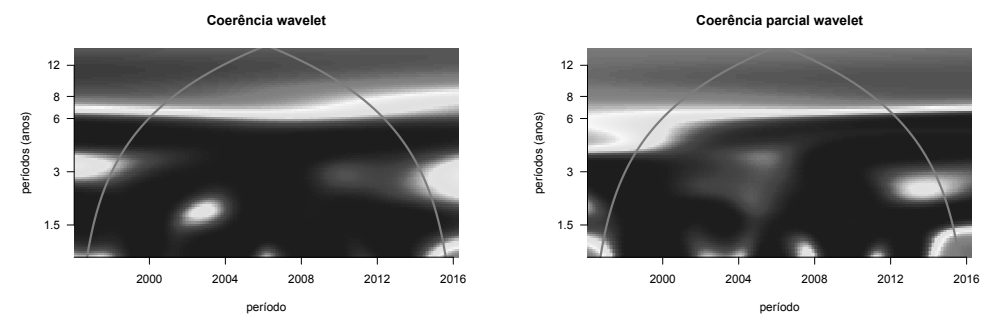

(c)
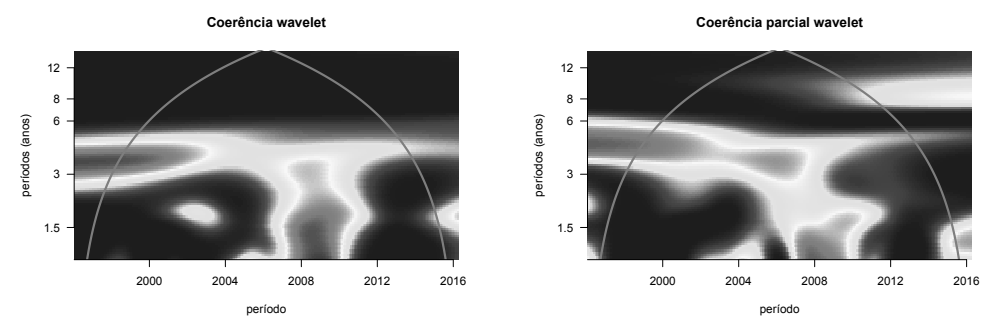

(d)
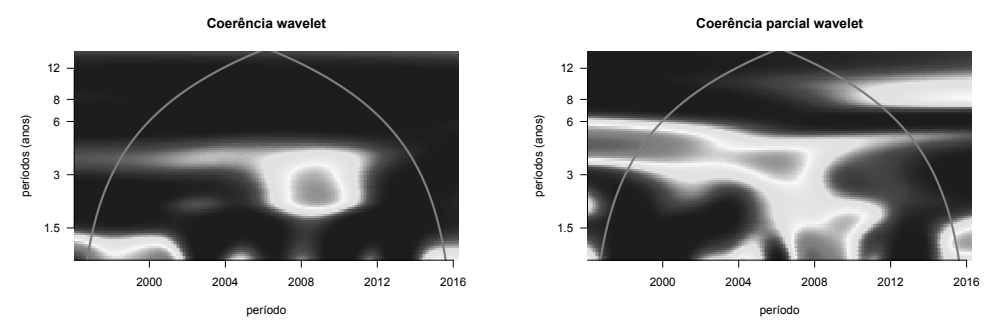

De forma geral e diante dos diversos resultados empíricos, observa-se, às vezes, resultados em direção ao esperado, seja a favor da relação positiva entre inflação e hiato do produto presente em uma curva de Phillips ou da hi- 
pótese de Fisher. Ainda, apesar de em algumas escalas a intrigante relação negativa entre retorno de ações e inflação se fazer presente, os resultados não corroboram a hipótese proxy de Fama (1981) no sentido de que a mesma seria induzida pela relação negativa entre a inflação e atividade econômica (estagflação). Contudo, os mesmos não são consistentes ao longo das frequências e tempo, pois significativa heterogeneidade é observada. Todavia, cabe destacar que, desde o início da crise de 2008, a relação entre inflação e produto nas economias mais avançadas tem sido substancialmente diferente da observada anteriormente, o que se pode esperar também da relação retorno de ações e inflação. Conforme Blanchard et al. (2016), existem evidências convincentes de que a relação entre hiato do produto e inflação já não é a mesma de antes, pois tem-se observado uma relação fraca (tanto em magnitude quanto em significância estatística) entre hiato do produto e inflação dada uma taxa de inflação esperada. Assim, torna-se relevante para a política monetária se essa relação mais fraca é uma tendência de longo prazo ou um resultado da crise em si, seja nas economias avançadas ou mesmo nas emergentes como a do Brasil.

\section{Considerações Finais}

A principal inovação deste trabalho foi utilizar a metodologia wavelet na análise da relação entre retorno de ações, inflação e atividade econômica brasileira. A aplicação desse método faz sentido pois a hipótese de Fisher (relação entre o retorno de ativos nominais e inflação), a ligação entre retorno real de ações e atividade econômica por meio do modelo do fluxo de caixa descontado, a hipótese proxy de Fama (1981) e a relação entre inflação e atividade econômica prescrita na curva de Phillips podem depender da escala de medida dessas variáveis decompostas e agregadas no curto, médio e longo prazos. A abordagem wavelet permite exatamente a decomposição das séries escala por escala.

Dessa forma, observa-se a relação temporal entre inflação, hiato do produto, taxa de crescimento da produção industrial e retorno do Ibovespa em diferentes escalas de tempo. Empregou-se a transformada wavelet discreta na versão MODWT. Como procedimento complementar, as séries também foram decompostas e analisadas na versão contínua. A investigação englobou a decomposição da variância das séries; o cômputo da correlação simples, parcial, múltipla e cruzada; a estimação de regressões em várias escalas; e a obtenção do hiato através da suavização bayesiana no método wavelet.

Em uma perspectiva geral, apesar de em algumas escalas a intrigante relação negativa entre retorno de ações e inflação se fazer presente, os resultados não corroboram a hipótese proxy de Fama (1981) no sentido de que a mesma seria induzida pela relação negativa entre a inflação e atividade econômica. Ainda, a relação entre retorno real de ações e atividade econômica não é independente da inflação, como implica a hipótese de Fisher.

Do ponto de vista mais descritivo, os resultados mostram evidências de que a estrutura das séries não é a mesma em termos de escala. Na inflação e hiato predominam as escalas de médio e longo prazos, enquanto na composição da taxa de crescimento da produção industrial e retorno real do índice acionário o componente de curto prazo é o determinante. A análise wavelet também revela que a relação entre as variáveis é bastante moderada ao longo do tempo e, quando existente, predomina nas escalas de médio e longo pra- 
zos e tende a se pronunciar nos momentos em que eventos anormais afetam significativamente a economia, como a crise financeira internacional do final da década de 2000 e a crise de confiança na economia brasileira no início dos anos 2000.

Em particular, os resultados empíricos levaram às seguintes conclusões, a saber: i) da análise de variância, os ciclos relevantes da inflação e do hiato do produto são superiores a 1 ano, ao passo que é de curto prazo o do retorno real do Ibovespa e do crescimento da produção industrial; ii) a análise da correlação mostrou muito pouca evidência de relação contemporânea, cruzada, parcial ou múltipla; iii) a regressão das séries em cada escala, obtidas da análise de multirresolução, confirmou os resultados anteriores no tocante ao curto e médio prazos; iv) a relação entre a inflação e o hiato do produto não é sensível ao modo como o hiato foi determinado, ou seja, tanto o hiato $\mathrm{HP}$ como o wavelet levam às mesmas conclusões, embora essas duas séries tenham estruturas diferentes. Por outro lado, a correlação com o retorno real do Ibovespa fica mais restrita ao curto prazo devido ao fato de o método de suavização utilizado na construção do hiato atribuir maior peso aos ruídos na escala mais fina.

A análise contínua complementou a abordagem discreta e, em um certo sentido, visto que os filtros aplicados são diferentes, serviu como um instrumento para testar a robustez dos resultados. De fato, as conclusões são similares. Porém, dos resultados dessa metodologia vale destacar os seguintes pontos que ficaram mais evidentes: i) após passar por um período onde estiveram presentes ciclos de alta frequência, a partir de 2004 a inflação entrou em uma fase de moderação, até 2010; ii) como esperado, o hiato do produto foi a variável mais afetada pela crise financeira internacional, manifestando-se ciclos de diversas ordens; iii) o espectro da taxa de crescimento da produção industrial é bastante concentrado na alta frequência, com formato relativamente uniforme durante o período estudado, o que pode sugerir que o processo de abertura comercial não influenciou a geração de picos nessa variável; e iv) a volatilidade de curto prazo do retorno real do índice acionário no período 1998 a 2003 foi bastante expressiva e o impacto da crise financeira internacional não foi drástico; v) ainda que a relação entre inflação e hiato do produto seja reduzida na amostra como um todo, corroborando a análise discreta, ela varia ao longo do tempo e já foi mais forte no passado.

\section{Agradecimentos}

Os autores agradecem ao parecerista anônimo pelos valiosos comentários e reforçam os agradecimentos presentes na Série de Trabalhos para Discussão do Banco Central, n. 471. O segundo autor é grato pelo suporte financeiro que tem recebido do CNPq, CAPES e FAPEMIG. Os eventuais erros remanescentes são de nossa inteira responsabilidade. As opiniões expressas neste trabalho são exclusivamente dos autores e não refletem, necessariamente, a visão do Banco Central do Brasil.

\section{Referências Bibliográficas}

Aguiar, L. F. \& Soares, M. J. (2011), The Continuous Wavelet Transform: A Primer, NIPE Working Papers 16/2011, NIPE - Universidade do Minho. 
URL: http://EconPapers.repec.org/RePEc:nip:nipewp:16/2011

Akerlof, G. A. (2002), 'Behavioral macroeconomics and macroeconomic behavior.', American Economic Review 92(3), 411-433.

Alagidede, P. \& Panagiotidis, T. (2012), 'Stock returns and inflation: Evidence from quantile regressions', Economics Letters 117(1), 283-286.

Blanchard, O., Dell'Ariccia, G. \& Mauro, P. (2016), Introdução: repensando a política macroeconômica II, in G. Akerlof, J. Stiglitz, D. Romer \& O. Blanchard, eds, 'O que nós aprendemos: a política macroeconômica no pós-crise', 1 edn, Rio de Janeiro: Alta Books, p. 352.

Bodie, Z. (1976), 'Common stocks as a hedge against inflation', Journal of Finance 31(2), 459-70.

Canova, F. \& Nicoló, G. D. (2000), 'Stock returns, term structure, inflation, and real activity: An international perspective', Macroeconomic Dynamics 4(03), 343-372.

Constantine, W. \& Percival, D. (2016), wmtsa: Wavelet Methods for Time Series Analysis. R package version 2.0-2.

URL: $h t t p s: / / C R A N . R$-project.org/package $=w m t s a$

Fama, E. (1981), 'Stock returns, real activity, inflation, and money', American Economic Review 71(4), 545-65.

URL: http://EconPapers.repec.org/RePEc:aea:aecrev:v:71:y:1981:i:4:p:545-65

Fama, E. F. \& Schwert, G. (1977), 'Asset returns and inflation', Journal of Financial Economics 5(2), 115-146.

URL: http://EconPapers.repec.org/RePEc:eee:jfinec:v:5:y:1977:i:2:p:115-146

Feldstein, M. (1980), 'Inflation and the stock market', American Economic Review 70(5), 839-47.

Fernández-Macho, J. (2012), 'Wavelet multiple correlation and crosscorrelation: A multiscale analysis of eurozone stock markets', Physica A: Statistical Mechanics and its Applications 391(4), 1097 - 1104.

Gallegati, M. (2008), 'Wavelet analysis of stock returns and aggregate economic activity', Computational Statistics \& Data Analysis 52(6), 3061 - 3074.

Gallegati, M. \& Gallegati, M. (2007), 'Wavelet Variance Analysis of Output in G-7 Countries', Studies in Nonlinear Dynamics E Econometrics 11(3), 1-25.

Gallegati, M., Gallegati, M., Ramsey, J. B. \& Semmler, W. (2011), 'The US wage phillips curve across frequencies and over time', Oxford Bulletin of Economics and Statistics 73(4), 489-508.

Gençay, R. \& Fan, Y. (2007), Unit Root Tests with Wavelets, MPRA Paper 9832, University Library of Munich, Germany.

URL: $h$ ttps://ideas.repec.org/p/pra/mprapa/9832.html

Gençay, R., Selçuk, F. \& Whitcher, B. (2002), An introduction to wavelets and other filtering methods in finance and economics, Academic Press, San Diego. 
Gentil, D. L. \& Messenberg, R. P. (2009), Crescimento econômico: produto potencial e investimento, Rio de Janeiro: IPEA.

Geske, R. \& Roll, R. (1983), 'The fiscal and monetary linkage between stock returns and inflation', Journal of Finance 38(1), 1-33.

Gultekin, N. B. (1983), 'Stock market returns and inflation: Evidence from other countries', Journal of Finance 38(1), 49-65.

Jaffe, J. F. \& Mandelker, G. (1976), 'The fisher effect for risky assets: an empirical investigation', Journal of Finance 31, 447-458.

Johnstone, I. M. \& Silverman, B. W. (2005a), 'Empirical bayes selection of wavelet thresholds', The Annals of Statistics 33(4), 1700-1752.

Johnstone, I. \& Silverman, B. (2005b), 'Ebayesthresh: R programs for empirical bayes thresholding', Journal of Statistical Software 12(1), 1-38.

Kim, S. \& In, F. (2005), 'The relationship between stock returns and inflation: new evidence from wavelet analysis', Journal of Empirical Finance 12(3), 435444.

Lee, B. S. (2010), 'Stock returns and inflation revisited: An evaluation of the inflation illusion hypothesis', Journal of Banking E Finance 34(6), 1257-1273.

Lundberg, C. (2015), Multiresolution Regression, Documentos de trabajo / working papers, Department of Economics, San Diego State University.

URL: https://editorialexpress.com/cgi-bin/conference/download.cgi?db_ name $=$ EEAESEM2016Epaper_id $=192$

Mankiw, N. G. \& Reis, R. (2010), Imperfect Information and Aggregate Supply, Handbook of Monetary Economics, Elsevier, chapter 5, pp. 183-229.

Mitra, S., Maheswari, V. \& Mitra, A. (2011), 'A wavelet filtering based estimation of output gap', Applied Mathematics and Computation 218(7), 3710 3722.

Modigliani \& Cohn, R. A. (1979), 'Inflation, rational valuation, and the market', Financial Analysts Journal 35(2), 24-44.

Nason, G. (2008), Wavelet Methods in Statistics with R, 1 edn, Springer.

Nelson, C. (1976), 'Inflation and rates of return on common stocks', Journal of Finance 31(2), 471-83.

Nunes, M. S., Costa Jr, N. C. A. d. \& Meurer, R. (2005), 'A relação entre o mercado de ações e as variáveis macroeconômicas: uma análise econômica para o Brasil', Revista Brasileira de Economia 59, 585 - 607.

Percival, D. B. \& Walden, A. T. (2000), Wavelet methods for time series analysis, Cambridge Univ. Press.

Phillips, A. W. (1958), 'The relation between unemployment and the rate of change of money wage rates in the united kingdom', Economica 25(100), 283299. 
Pimentel, E. A. (2013), 'A wavelets-based analysis of the phillips curve hypothesis for the Brazilian economy, 1980-2011', Economia Aplicada 17, 90 114.

Pimentel, E. \& Silva, J. (2011), 'Decomposição de ondaletas, análise de volatilidade e correlação para índices financeiros', Estudos Econômicos (São Paulo) 41(2), 441-462.

Polanco-Martínez, J. M. \& Abadie, L. M. (2016), 'Analyzing crude oil spot price dynamics versus long term future prices: A wavelet analysis approach', Energies 9(12).

Roesch, A. \& Schmidbauer, H. (2014), WaveletComp: Computational Wavelet Analysis. R package version 1.0.

URL: https://CRAN.R-project.org/package $=$ WaveletComp

Silverman, B. W. (2012), EbayesThresh: Empirical Bayes Thresholding and Related Methods. R package version 1.3.2.

URL: https://CRAN.R-project.org/package=EbayesThresh

Terra, P. R. S. (2006), 'Inflação e retorno do mercado acionário em países desenvolvidos e emergentes', Revista de Administração Contemporânea 10, 133 -158 .

Tiwari, A. K., Oros, C. \& Albulescu, C. T. (2014), 'Revisiting the inflation-output gap relationship for France using a wavelet transform approach', Economic Modelling 37, $464-475$.

Torrence, C. \& Compo, G. P. (1998), 'A practical guide to wavelet analysis', Bulletin of the American Meteorological Society 79(1), 61-78.

Whitcher, B. (2015), waveslim: Basic wavelet routines for one-, two- and threedimensional signal processing. $\mathrm{R}$ package version 1.7.5.

URL: https://CRAN.R-project.org/package=waveslim 


\section{A Transformada Discreta}

O tratamento formal da transformada wavelets discreta pode ser visto em Percival \& Walden (2000), Gençay et al. (2002) e Nason (2008), que são referências comumente citadas em trabalhos nessa área. A implementação do método ocorreu por meio dos pacotes wmtsa e waveslim pela plataforma $\mathrm{R}$, desenvolvidos, respectivamente, por Constantine \& Percival (2016) e Whitcher (2015).

Os coeficientes wavelets $\widetilde{d}_{j, t}$ e de escala $\widetilde{s}_{j, t}$ da MODWT no nível $j$ e no índice $t$ são, respectivamente, definidos por:

$$
\begin{aligned}
& \widetilde{d}_{j, t}=\sum_{l=0}^{L-1} \widetilde{h}_{l} \widetilde{s}_{j-1, t-2^{j-1} l \bmod N}, \\
& \widetilde{s}_{j, t}=\sum_{l=0}^{L-1} \widetilde{g}_{l} \widetilde{s}_{j-1, t-2^{j-1} l \bmod N} .
\end{aligned}
$$

Para uma série qualquer $X_{0}, X_{1} \ldots X_{N-1}$, a operação $X_{l \bmod N}$ aumenta a dimensão da série de modo circular, por exemplo, $X_{-1}=X_{N-1}, X_{-2}=X_{N-2}, X_{N}=$ $X_{0}, X_{N+1}=X_{1}$, etc. Por definição, $\widetilde{s_{0, t}}=X_{0}, X_{1} \ldots X_{N-1}$, com $t=0,1 \ldots N-1$. A variável $L$ corresponde à dimensão dos filtros $g$ e $h$. No caso do filtro wavelet $\mathrm{LA}(8), L=8$.

A variância não enviesada é calculada da seguinte forma:

$$
\widehat{v}_{X}^{2}\left(\lambda_{j}\right)=\frac{1}{M_{j}} \sum_{t=L_{j}-1}^{N-1} \widetilde{d}_{j, t}^{2},
$$

onde $\lambda_{j}=2^{j-1}, L_{j}=\left(2^{j}-1\right)(L-1)+1$ e $M_{j}=N-L_{j}+1$. A variável $M_{j}$ controla os coeficientes de borda gerados no processo de extensão circular da série.

Considerando $Q_{n}(p)$ como o $p$ X100 ponto percentual de uma distribuição qui-quadrado com $n$ graus de liberdade, o intervalo de confiança da variância, aproximado de $100(1-2 p) \%$, é dado por:

$$
\left[\frac{n \widehat{v}_{X}^{2}\left(\lambda_{j}\right)}{Q_{n}(1-p)}, \frac{n \widehat{v}_{X}^{2}\left(\lambda_{j}\right)}{Q_{n}(p)}\right]
$$

Supondo duas séries temporais X e Y, um estimador não enviesado da correlação wavelet na escala $\lambda_{j}$, obtido via MODWT, é calculado como:

$$
\widehat{\rho}_{X Y}\left(\lambda_{j}\right)=\frac{\operatorname{cov}\left(\widetilde{d}_{j, t}^{X}, \widetilde{d}_{j, t}^{Y}\right)}{\sqrt{\left(\widehat{v}_{X}^{2}\left(\lambda_{j}\right)\right)\left(\widehat{v}_{Y}^{2}\left(\lambda_{j}\right)\right)}},
$$

onde,

$$
\operatorname{cov}\left(\widetilde{d}_{j, t}^{X}, \widetilde{d}_{j, t}^{Y}\right)=\widehat{\gamma}_{X Y}\left(\lambda_{j}\right)=\frac{1}{M_{j}} \sum_{t=L_{j}-1}^{N-1} \widetilde{d}_{j, t}^{X} \widetilde{d}_{j, t}^{Y} .
$$

Finalmente, a correlação cruzada entre X e Y na escala $\lambda_{j}$ e defasagem $v$ é dada por: 


$$
\widehat{\rho}_{X Y, v}\left(\lambda_{j}\right)=\frac{\widehat{\gamma}_{X Y, v}\left(\lambda_{j}\right)}{\sqrt{\left(\widehat{v}_{X}^{2}\left(\lambda_{j}\right)\right)\left(\widehat{v}_{Y}^{2}\left(\lambda_{j}\right)\right)}} .
$$




\section{B Transformada Contínua}

O tratamento formal da transformada wavelet contínua pode ser visto em, por exemplo, Percival \& Walden (2000). A implementação do método ocorreu por meio do pacote WaveletComp pela plataforma R, desenvolvido por Roesch \& Schmidbauer (2014). A apresentação a seguir é baseada em Torrence \& Compo (1998), Aguiar \& Soares (2011) e Roesch \& Schmidbauer (2014).

Nesse artigo empregou-se a função wavelet-mãe de Morlet, com frequência angular igual a 6, o que permite interpretar a escala como o inverso da frequência, definida por:

$$
\psi(t)=\pi^{-1 / 4} e^{6 i t} e^{-t^{2} / 2} .
$$

Dado $\psi$, a transformada contínua de uma série temporal $x(t)$ é definida como a convolução da série com um conjunto de funções wavelets filhas, geradas a partir da função wavelet mãe pela translação no tempo $(\tau)$ e mudança na escala $(s)$ :

$$
W_{x}(\tau, s)=\frac{1}{\sqrt{|s|}} \int_{-\infty}^{\infty} x(t) \bar{\psi}\left(\frac{t-\tau}{s}\right) d t
$$

com $\bar{\psi}$ denotando o conjugado complexo e $\frac{1}{\sqrt{|s|}}$ correspondendo a uma constante de normalização, que iguala a energia das ondaletas filhas e mãe, garantindo que tenham variância unitária.

A transformada wavelet da função base de Morlet decompõe e descreve a série no domínio da frequência, possibilitando a análise em diversas escalas de frequência e de tempo.

Uma medida da distribuição da variância no plano tempo-frequência pode ser obtida do quadrado da amplitude de um componente periódico da série temporal, interpretado como o espectro de energia wavelet em um local específico, cuja definição é:

$$
W P S_{x}(\tau, s)=\frac{1}{s}\left|W_{x}(\tau, s)\right|^{2} .
$$

Como a base Morlet tem valor complexo, a transformada da série também é complexa, o que permite escrever $W_{x}(\tau, s)$ na forma polar, cuja fase é função da parte imaginária $(\operatorname{Im})$ e real $(\mathfrak{R e})$ :

$$
\phi_{x}(\tau, s)=\tan ^{-1}\left(\frac{\operatorname{Im}\left(W_{x}(\tau, s)\right)}{\operatorname{Re}\left(W_{x}(\tau, s)\right)}\right) .
$$

A transformada coerência em ondaletas entre duas séries temporais é definida como a razão entre o espectro cruzado e o produto dos espectros individuais:

$$
R_{x y}^{2}=\frac{\left|S\left(W_{x y}(\tau, s)\right)\right|^{2}}{S\left(W P S_{x}(\tau, s)\right) S\left(W P S_{y}(\tau, s)\right)},
$$

onde a transformada cruzada wavelet $\left(W_{x y}\right)$ é dada por:

$$
W_{x y}(\tau, s)=\frac{1}{s} W_{x}(\tau, s) \overline{W_{y}}(\tau, s),
$$


e $S$ é um operador de suavização no tempo $(\tau)$ e escala $(s)$.

A diferença de fase é definida como:

$$
\phi_{x, y}(\tau, s)=\tan ^{-1}\left(\frac{\left.\operatorname{Im}\left(W_{x y}(\tau, s)\right)\right)}{\left.\operatorname{Re}\left(W_{x y}(\tau, s)\right)\right)}\right) .
$$

